Article

\title{
Theoretical and Experimental Spectroscopic Analysis of Cyano-Substituted Styrylpyridine Compounds
}

\author{
Maria Eugenia Castro ${ }^{1}$, Maria Judith Percino ${ }^{1}$, Victor M. Chapela ${ }^{1}$, Margarita Ceron ${ }^{1}$, \\ Guillermo Soriano-Moro ${ }^{1}$, Jorge Lopez-Cruz ${ }^{2}$ and Francisco J. Melendez ${ }^{2, *}$
}

1 Chemistry Center, Institute of Sciences, Autonomous University of Puebla, Complex of Sciences, ICUAP, 103H, 22 Sur y San Claudio, University City, Puebla City, Pue.-72570, Mexico;

E-Mails: mareug.castro@correo.buap.mx (M.E.C.); judith.percino@correo.buap.mx (M.J.P.); victor.chapela@correo.buap.mx (V.M.C.); margarita.ceron@correo.buap.mx (M.C.); jesus.soriano@correo.buap.mx (G.S.-M.)

2 Theoretical Chemistry Laboratory, Investigation Center, Department of Physical Chemistry, Faculty of Chemical Sciences, Autonomous University of Puebla, 105I, San Claudio y 22 Sur, University City, Puebla City, Pue.-72570, Mexico; E-Mail: jorge.lc@gmail.com

* Author to whom correspondence should be addressed; E-Mail: francisco.melendez@correo.buap.mx; Tel.: +55-222-229-5500 (ext. 2830); Fax: +55-222-229-5584.

Received: 14 November 2012; in revised form: 30 December 2012 / Accepted: 23 January 2013 / Published: 18 February 2013

\begin{abstract}
A combined theoretical and experimental study on the structure, infrared, UV-Vis and ${ }^{1} \mathrm{H}$ NMR data of trans-2-( $m$-cyanostyryl)pyridine, trans-2-[3-methyl-( $m$ cyanostyryl $)$ pyridine and trans-4-( $m$-cyanostyryl $)$ pyridine is presented. The synthesis was carried out with an efficient Knoevenagel condensation using green chemistry conditions. Theoretical geometry optimizations and their IR spectra were carried out using the Density Functional Theory (DFT) in both gas and solution phases. For theoretical UV-Vis and ${ }^{1} \mathrm{H}$ NMR spectra, the Time-Dependent DFT (TD-DFT) and the Gauge-Including Atomic Orbital (GIAO) methods were used, respectively. The theoretical characterization matched the experimental measurements, showing a good correlation. The effect of cyano- and methyl- substituents, as well as of the $\mathrm{N}$-atom position in the pyridine ring on the UV-Vis, IR and NMR spectra, was evaluated. The UV-Vis results showed no significant effect due to electron-withdrawing cyano- and electron-donating methyl-substituents. The $N$-atom position, however, caused a slight change in the maximum absorption wavelengths. The IR normal modes were assigned for the cyano- and methyl-groups. ${ }^{1} \mathrm{H}$ NMR spectra showed the typical doublet signals due to protons in the trans position of a double bond. The
\end{abstract}


theoretical characterization was visibly useful to assign accurately the signals in IR and ${ }^{1} \mathrm{H}$ NMR spectra, as well as to identify the most probable conformation that could be present in the formation of the styrylpyridine-like compounds.

Keywords: styrylpyridine compounds; DFT calculations; IR spectroscopy; UV-Vis spectroscopy; NMR spectroscopy

\section{Introduction}

Low molecular weight and oligomeric organic compounds with optical or electrical properties have been widely used as dyes in organic electronic devices, including organic light emitting diodes (OLEDs), solar cell organic semiconductor lasers, etc. [1-6]. Typically, these dyes have a donor (D) $-\pi-$ acceptor (A) structure that controls their photophysical properties $[2,7,8]$. On the other hand, it is well know that cyano-substituted compounds show good optical and electrical properties due to their high electron affinities [9]. In particular, some cyano-substituted compounds have been reported, which show unique enhanced emission rather than fluorescence quenching in the solid state [10]. However, pyridine is an important electron-acceptor group, due to its high electron affinity. Dailey S. et al. described poly(2,5-pyridinediyl) (PPY) as an efficient electron transport layer in bilayer polymeric LEDs. The OLEDs with a PPY layer exhibited external quantum efficiency 60-times greater than those of similar devices without a PPY layer [11]. Epstein et al. described poly(p-pyridine)- and poly( $p$-pyridyl vinylene)-based polymers as emissive layers in light-emitting devices [12]. Bartholomew et al. [13] studied model compounds, such as phenylated PPV, also with the electron withdrawing cyano group attached to the olefin, and they can also be used as a model cyano substitute (CN-PPV).

On the other hand, the effect of introducing nitrogen atoms in the aromatic rings of trans-1,2-diarylethylenes has been widely investigated in order to study the effect of heteroatoms on the excited state properties of stilbene, related diarylethenes and $n$-styrylpyridines [14-16]. Model compounds in trans conformation or with the group $\mathrm{CN}$ attached to double bond or in the aromatic ring [17-21] have been studied to comprehend the effect in the optics and electronic properties. One of our studies on styrylpyridines derivatives was on 2,6-distyrylpyridine [22,23]. The characterization results by X-ray showed that although the molecule is plane, it did not exhibit a total delocalization of its electrons through the whole molecule. Also, the results showed that depending on the trans spatial arrangement of double bonds, there were three possible conformations. The theoretical calculations reported showed the conformational and structural analyses of 2,6-distyrylpyridine conformations using $a b$ initio methods, as well as methods based on density functional theory, DFT [23]. The results determined that the conformation depends on the double bond orientation by the trans proton steric effect with protons in the ortho position of the phenyl or with pyridine groups. For our study, these molecules are chosen, because they contain a cyano group as a strong acceptor attached to the aromatic ring, a pyridine group as a weak acceptor (in $o$ - and $p$-position) through double bonding and a methyl moiety as a donor by the inductive effect, to evaluate which kind of structure, $D-\pi-A$ or $A-\pi-A$, is present. 
Several styrylpyridine-like compounds-2-styrylpyridine, its derivatives and intermediates [24-27], 4-styrylpyridine and its intermediates [27-29], 2,6-distyrylpyridine [23,27], pyridinevinylenes [30] and phenylpyridylacrylonitriles [19] — have been synthesized under green chemistry conditions. Some have been characterized by X-ray diffraction [22,24-29], IR [19,22,25-30], ${ }^{1} \mathrm{H}-\mathrm{NMR}$ [19,24-30], UV-Vis [19,28], mass spectroscopy [19,27] and complementary theoretical studies [23,31]. Theoretical calculations on 2,6-distyrylpyridine [23,31], 4-styrylpyridine [32,33] and 2-styrylpyridine and derivatives [34] have been carried out using $a b$ initio and Density Functional Theory (DFT) approximations.

Atalay et al. [31] obtained geometric parameters, IR and ${ }^{1} \mathrm{H}$ and ${ }^{13} \mathrm{C} \mathrm{NMR}$ spectra for 2,6-distyrylpyridine using Hartree-Fock (HF) and B3LYP methods with the 6-31G(d) basis set. In this work, the B3LYP calculations fit the experimental data better than HF-derived values in evaluating vibrational frequencies and geometrical parameters [31]. Melendez et al. [23], carried out a study of three conformational structures of 2,6-distyrylpyridine using HF, second-order Moller-Plesset (MP2) and B3LYP methods with 6-31G(d,p) and cc-pVDZ basis sets. The authors indicated that B3LYP and MP2 methods with the cc-pVDZ basis set would be good choices for structural, stability and reactivity analyses for these kinds of compounds [23]. Daku et al. [32,33] analyzed the 4-styrylpyridine cis and trans isomers using HF, MP2 and coupled cluster (CC) ab initio methods, DFT and Molecular Dynamics (MD) methods. Similar results were found for the geometry and energy determination using these different methods, allowing the authors to predict the molecular structure as planar at the energy minimum corresponding to the trans conformation [32]. TD-DFT was used for calculating the absorption spectra of both isomers [33], where the main absorption band was predicted at $314.5 \mathrm{~nm}$, due to the double bond in the trans isomer, which originated from the $\mathrm{S}_{0}$ to $\mathrm{S}_{1}$ transition. On the other hand, trans-4-(m-cyanostyryl)pyridine was recently studied using DFT methods [34], in order to predict the maximum absorption using the TD-DFT approach. The absorption maximum was calculated to be $307.2 \mathrm{~nm}$, similar to the values obtained by Daku et al. [33] and the experimental value of $304 \mathrm{~nm}$ [30] for 4-styrylpyridine. Castro et al. [34] also reported that the calculated values for the maximum absorption for the 2-styrylpyridine and cyano- and methyl-substituted derivatives by DFT methods were close to experimentally determined values.

DFT calculations, specifically hybrid methods, namely B3LYP, PBE and PBE0, have been shown to be a good approximation method for providing accurate molecular parameters, infrared spectrum assignment, ${ }^{1} \mathrm{H}$ chemical shifts and UV-Vis spectrum, and are in good agreement with experimental data for styrylpyridine-like compounds [23,31-34] and other organic conjugated compounds [35-39].

In this work, we present the synthesis and spectroscopic characterization of three cyano-substituted styrylpyridine compounds, which were obtained using green chemistry conditions. These structures are derivatives of 2- and 4-styrylpyridine with the $-\mathrm{C} \equiv \mathrm{N}$ group attached at the meta position of the phenyl ring. These compounds were characterized theoretical and experimentally by $\mathrm{IR},{ }^{1} \mathrm{H}$ NMR and UV-Vis spectroscopy. Optimized structural parameters were obtained using the Density Functional Theory (DFT), performing B3LYP/6-311 + G(d,p) theoretical calculations in both gas and solution phases [34]. Infrared frequencies (IR) spectra, UV-Vis transitions and ${ }^{1} \mathrm{H}$ NMR shifts were obtained. Our analyses of these soluble styrylpyridine model compounds allowed us to gain insights into the role of the substituents and position of the $N$-atom in determining the spectroscopic characteristics of this class of compounds. 


\section{Computational Methodology}

The three styrylpyridine-like model compounds were investigated by DFT theoretical calculations. The molecular structures and the numerical conventions used for carrying out the theoretical calculations are shown in Figure 1.

Figure 1. Molecular structure and numerical conventions of trans-2-( $m$-cyanostyryl)pyridine (IIIa), trans-2-[3-methyl-(m-cyanostyryl)]pyridine (IIIb) and trans-4-(m-cyanostyryl) pyridine $($ IIIc).
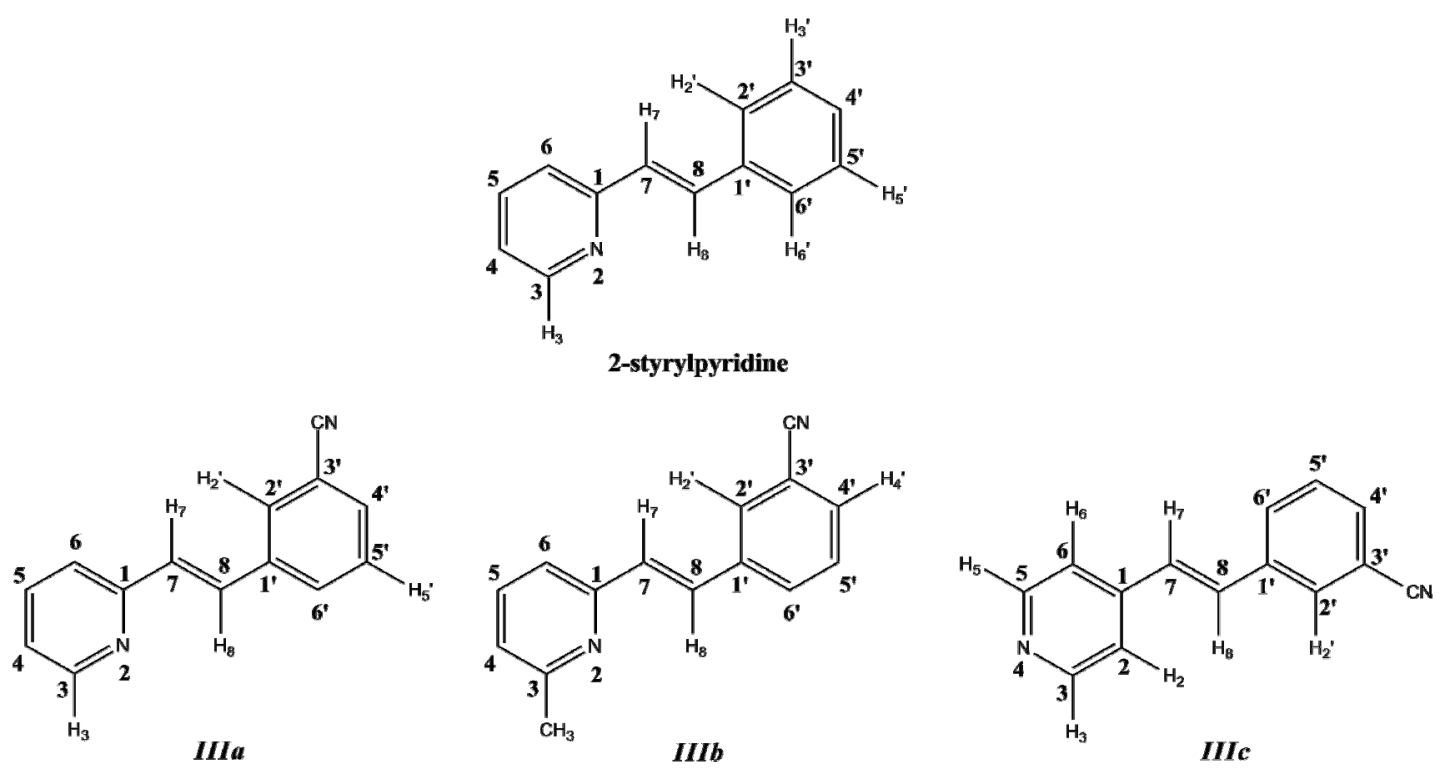

The optimization calculations in gas and solution phases were performed by the DFT method taking into account the electron correlation contribution, which is especially important in conjugated systems. B3LYP functional [40,41] with the 6-311 + G(d,p) basis set [42] was used. The solvent effect of $\mathrm{CHCl}_{3}$ (with the dielectric constant $\varepsilon=4.71$ ) was included by using the Polarizable Continuum Model (PCM) [43].

Vibrational frequencies were calculated at the same theory level as the optimization calculations to ensure the minima structures of the compounds and to obtain the vibrational analysis using the scale factor of 0.9648 [44]. Electronic transition energies were calculated by the TD-B3LYP/6-31G(d) method [45-48] from the B3LYP/6-311 + G(d,p) optimized geometries to reproduce UV-Vis spectroscopic transitions. Finally, ${ }^{1} \mathrm{H}$ NMR chemical shifts were obtained by the Gauge-Independent Atomic Orbital (GIAO) approach [49,50] in the B3LYP/6-31 + G(d,p)//B3LYP/6-311 + G(d,p) level. All the calculations were carried out in the Gaussian 09 program [51].

\section{Results and Discussion}

\subsection{Synthesis}

Compounds IIIa-IIIc were obtained from the corresponding methylpyridine $\boldsymbol{I}$ with the corresponding aldehyde $\boldsymbol{I}$, as is described in the Experimental section. The condensation reaction scheme is presented in Figure 2. 
Figure 2. Synthesis of trans-2-(m-cyanostyryl)pyridine (IIIa), trans-2-[3-methyl-(mcyanostyryl)]pyridine (IIIb) and trans-4-(m-cyanostyryl)pyridine (IIIc).
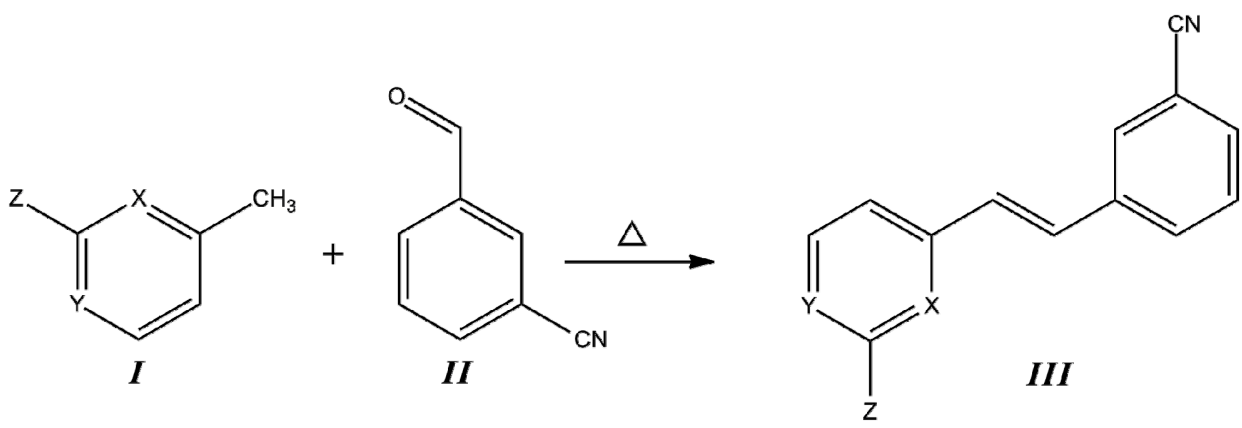

\begin{tabular}{c|ccl}
$\boldsymbol{I}, \boldsymbol{I I I}$ & $\mathrm{X}$ & $\mathrm{Y}$ & $\mathrm{Z}$ \\
\hline $\boldsymbol{a}$ & $\mathrm{N}$ & $\mathrm{C}$ & $\mathrm{H}$ \\
$\boldsymbol{b}$ & $\mathrm{N}$ & $\mathrm{C}$ & $\mathrm{CH}_{3}$ \\
$\boldsymbol{c}$ & $\mathrm{C}$ & $\mathrm{N}$ & $\mathrm{H}$
\end{tabular}

2-Styrylpyridine was synthesized according to the previously reported method [24,27]. The temperature, reaction time and the presence of the $-\mathrm{C} \equiv \mathrm{N}$ and $-\mathrm{CH}_{3}$ substituents play important roles in the product formation, as well as the presence of either the ortho- or para-position pyridine. Table 1 shows the yields and measured properties of each compound.

Table 1. Conditions, yields and properties of the styrylpyridine-like model compounds $($ IIIa-IIIc)

\begin{tabular}{|c|c|c|c|c|c|c|}
\hline Compound & Temp & Time & Yield & Appearance & Melting point & Solubility \\
\hline & ${ }^{\circ} \mathrm{C}$ & $\mathrm{h}$ & $\%$ & & ${ }^{\circ} \mathrm{C}$ & \\
\hline IIIa & 120 & 30 & 72 & white powder & $77-78$ & $\begin{array}{c}\text { toluene, } \mathrm{CHCl}_{3} \text {, THF, acetone, } \\
\text { EtOH, } \mathrm{MeOH}, \mathrm{DMSO}\end{array}$ \\
\hline$I I I b$ & 140 & 22 & 59 & beige powder & $68-78$ & $\begin{array}{c}\mathrm{CHCl}_{3}, \mathrm{THF} \text {, acetone, } \mathrm{MeOH} \text {, } \\
\text { DMSO }\end{array}$ \\
\hline IIIc & 120 & 30 & 63 & beige powder & $63-65$ & $\begin{array}{c}\text { hexane, cyclohexane, toluene, } \\
\mathrm{CHCl}_{3}, \mathrm{THF} \text {, acetone, EtOH, } \\
\mathrm{MeOH} \text {, DMSO }\end{array}$ \\
\hline
\end{tabular}

Under these reaction conditions, we obtained IIIa-IIIc in almost the same yield as reported for 2-styrylpyridine [24,27] under the same conditions. Recent studies have described the use of Knoevenagel condensation in the synthesis of several substituted stilbenes in the absence of catalyst and solvent [19,22,24-30]. However, compared with the conditions used for reactions of pyridylacetonitrile with benzaldehyde, we observed that the effect of the $-\mathrm{C} \equiv \mathrm{N}$ group on the reactivity was dependent on its site of attachment in the structure. The reactivity was more pronounced for

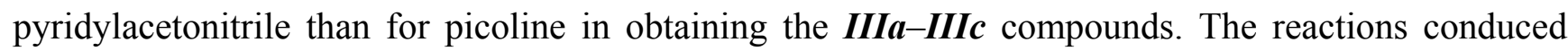
without catalyst and solvent gave better yields, even at room temperature $[19,30]$, when the $-\mathrm{C} \equiv \mathrm{N}$ group was located on the $-\mathrm{CH}_{2} \mathrm{CN}$ than when located in the aromatic aldehyde. According to the results from the three reactions of Table 1 , the reactivity behavior is $-\mathrm{CH}_{3}$ moiety $<p$-position $<o$-position on pyridine ring due to the inductive effect. Systems with $\pi$-conjugated units provide an effective 
pathway for the efficient push-pull charge transfer between donor and acceptor groups. Styrylpyridine-like materials are expected to have different applications in photochemistry and fluorescence processes when the donor-acceptor or acceptor-acceptor is introduced in the phenyl rings in order to extend the conjugation over the whole molecule.

\subsection{Molecular Structures}

Optimized parameters were obtained by the B3LYP/6-311 $+\mathrm{G}(\mathrm{d}, \mathrm{p})$ level for the three model compounds. Previous tests were carried out for the isomers of these molecules with the $-\mathrm{C} \equiv \mathrm{N}$ group attached to the equivalent phenyl ring in the meta-position [34]. The rotamers showed energy values similar to each other $\left(\sim 1 \mathrm{~kJ} \mathrm{~mol}^{-1}\right)$; however, the energy barriers were $\sim 20$ to $25 \mathrm{~kJ} \mathrm{~mol}^{-1}$ [34] for the torsion motion of the cyano-substituted phenyl ring. The energetically most stable isomers of molecules IIIa-IIIc were those with the $-\mathrm{C} \equiv \mathrm{N}$ group attached in position $\mathrm{C}\left(3^{\prime}\right)$. Molecules IIIa and III b displayed an orientation anti to the $-\mathrm{C} \equiv \mathrm{N}$ group with respect to the $\mathrm{N}$-atom of the pyridine ring, but for IIIc, the orientation was different (Figure 1).

In this work, a two-dimensional conformational analysis was carried out for evaluating simultaneously the effect of the torsion of phenyl group, $\theta 1$, and the pyridine group, $\theta 2$. The two conformational coordinates were defined as dihedrals $\theta 1$, between atoms $C(7)-C(8)-C\left(1^{\prime}\right)-C\left(2^{\prime}\right)$ for 2-styrylpyridine, III a and IIIb and $\mathrm{C}(7)-\mathrm{C}(8)-\mathrm{C}\left(1^{\prime}\right)-\mathrm{C}\left(6^{\prime}\right)$ for IIIc and $\theta 2$, between atoms $\mathrm{N}(2)-\mathrm{C}(1)-\mathrm{C}(7)-\mathrm{C}(8)$ for 2-styrylpyridine and III a and IIIb and $\mathrm{C}(2)-\mathrm{C}(1)-\mathrm{C}(7)-\mathrm{C}(8)$ for IIIc (Figure 1). For the four molecules, a grid of points was generated on each conformational coordinate using increments of $30^{\circ}$ in a range of $0^{\circ}-180^{\circ}$. At each grid point, the conformational coordinates were kept frozen, whereas the rest of the structure was fully relaxed. Figure 3 shows the isocontour potential energy maps as the function $\theta 1$ and $\theta 2$ torsional angles described. The interval between isocontour lines is $10 \mathrm{~kJ} \mathrm{~mol}^{-1}$, and the data refer to the minimum value. Red zones correspond to lower energy zones, whereas blue zones correspond to higher energy zones. The structures of the minima and maximum are included in the figure.

Figure 3, for the case of 2-styrylpyridine, shows double minima arising from the symmetric torsion of the phenyl ring; therefore, equivalent minima for $(\theta 1, \theta 2)\left(0^{\circ}, 0^{\circ}=180^{\circ}, 0^{\circ}\right.$ and $0^{\circ}, 180^{\circ}=180^{\circ}$, $\left.180^{\circ}\right)$ are found. The global minimum $\left(0^{\circ}, 0^{\circ}\right)$ and the local minimum $\left(0^{\circ}, 180^{\circ}\right)$ were located on the potential energy map for the torsion of the pyridine group with a relative energy between rotamers of $4.65 \mathrm{~kJ} \mathrm{~mol}^{-1}$; see Table 2. For IIIa and IIIb, in addition to the minima due to the torsion of the pyridine ring, another two minima were located due to the torsion of the cyano-substituted phenyl. So, the rotamer $\left(180^{\circ}, 0^{\circ}\right)$ is almost energetically equivalent to global minimum $\left(0^{\circ}, 0^{\circ}\right)$ in less than $1 \mathrm{~kJ} \mathrm{~mol}^{-1}$, while two local minima in $\left(0^{\circ}, 180^{\circ}\right)$ and $\left(180^{\circ}, 180^{\circ}\right)$ were found with energy differences of about $1 \mathrm{~kJ} \mathrm{~mol}^{-1}$ between them (Table 2). For IIIc, the position of the $N$-atom in the pyridine ring provided two symmetric minima with respect to the pyridine torsion, while the global minimum was found for the $\left(0^{\circ}, 180^{\circ}\right)$ and the local minimum for $\left(0^{\circ}, 0^{\circ}\right)$ rotamers. For the four molecules, the activation barriers were found at $\sim 34$ to $46 \mathrm{~kJ} \mathrm{~mol}^{-1}$, corresponding to structures with $(\theta 1, \theta 2)=\left(90^{\circ}, 90^{\circ}\right)$. 
Figure 3. Isocontour potential energy maps as a function of $\theta 1$ and $\theta 2$ torsional angles of 2-styrylpyridine, trans-2-(m-cyanostyryl)pyridine (IIIa), trans-2-[3-methyl- $(m-$ cyanostyryl)]pyridine (IIIb) and trans-4-(m-cyanostyryl)pyridine (IIIc) obtained at the B3LYP/6-311 + G(d,p) theory level. The structures at the minima and maximum are included.
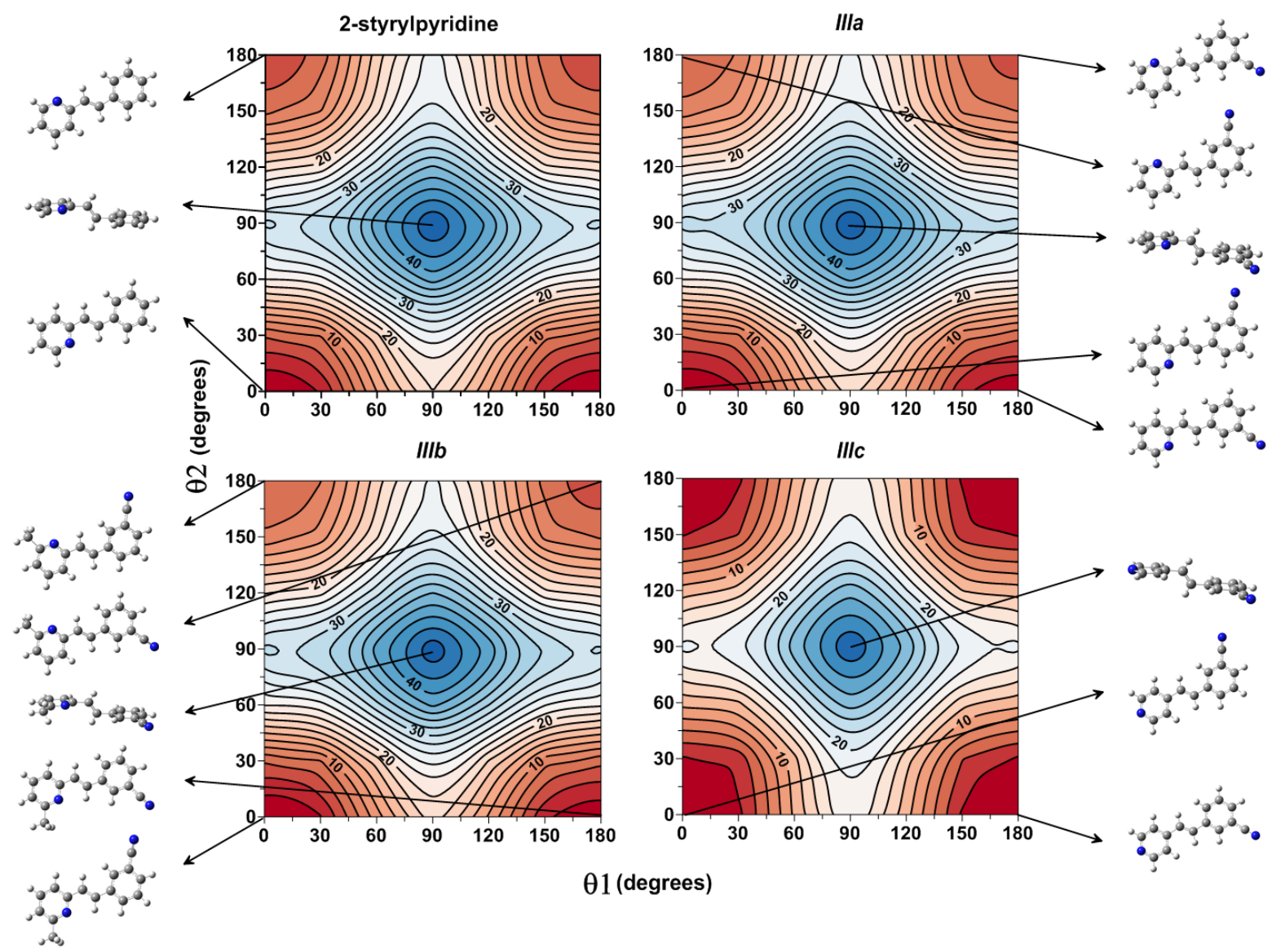

In order to complement the conformational study, which provides results based essentially on enthalpy values, we achieved a thermostatistical analysis to account for entropic effects. The population of the different rotamers was calculated at room temperature by using the technique developed by Niño et al. [52]. The populations (in percent) were calculated from the relative energies obtained at the B3LYP/6-311 $+\mathrm{G}(\mathrm{d}, \mathrm{p})$ theory level in Figure 3. The results collected in Table 2 show that for 2-styrylpyridine, the population for the global minimum is considerably larger (11.85\%) than that for the local minimum $(1.80 \%)$, confirming that the rotamer that is energetically more stable $\left(0^{\circ}, 0^{\circ}\right)$ is the most populated. For $\boldsymbol{I I I a}$ and $\boldsymbol{I I I \boldsymbol { b }}$, it was found that the minima $\left(0^{\circ}, 0^{\circ}\right)$ and $\left(180^{\circ}, 0^{\circ}\right)$ energetic equivalents had populations with values of less than $1.5 \%$ of the difference between them, while the minima corresponding to the rotamers $\left(0^{\circ}, 180^{\circ}\right)$ and $\left(180^{\circ}, 180^{\circ}\right)$ gave small population values (Table 2). Finally, for IIIc, the difference in population between the global and local minima is less than $1 \%$. In all cases, the rotamers with maximum energies gave a population of $0 \%$, as was expected. 
Table 2. Relative energies in $\left(\mathrm{kJ} \mathrm{mol}^{-1}\right)$ calculated at the B3LYP/6-311 + G(d,p) theory level and populations in (\%) of the styrylpyridine-like model compounds (IIIa-IIIc) for different rotamers, with $\theta 1$ and $\theta 2$ dihedral angles in $\left(^{\circ}\right)$.

\begin{tabular}{|c|c|c|c|c|c|}
\hline \multicolumn{3}{|c|}{ 2-Styrylpyridine } & \multicolumn{3}{|c|}{ IIIa } \\
\hline$\theta 1, \theta 2$ & Relative energy & Population & $\theta 1, \theta 2$ & Relative energy & Population \\
\hline $0.0,0.0$ & 0.000 & 11.847 & $0.0,0.0$ & 0.000 & 6.854 \\
\hline $0.0,180.0$ & 4.647 & 1.797 & $0.0,180.0$ & 6.459 & 0.076 \\
\hline $30.0,30.0$ & 8.113 & 0.087 & $30.0,30.0$ & 7.903 & 0.064 \\
\hline $60.0,60.0$ & 31.821 & 0.002 & $60.0,60.0$ & 31.532 & 0.001 \\
\hline $90.0,0.0$ & 20.033 & 0.008 & $90.0,0.0$ & 19.088 & 0.003 \\
\hline $90.0,90.0$ & 45.815 & 0.000 & $90.0,90.0$ & 45.658 & 0.000 \\
\hline $90.0,180.0$ & 25.074 & 0.009 & $90.0,180.0$ & 24.916 & 0.003 \\
\hline $180.0,0.0$ & 0.000 & 11.847 & $180.0,0.0$ & 0.630 & 5.254 \\
\hline $180.0,180.0$ & 4.647 & 1.797 & $180.0,180.0$ & 5.277 & 1.231 \\
\hline \multicolumn{3}{|c|}{ IIIb } & \multicolumn{3}{|c|}{ IIIc } \\
\hline$\theta 1, \theta 2$ & Relative energy & Population & $\theta 1, \theta 2$ & Relative energy & Population \\
\hline $0.0,0.0$ & 0.000 & 6.581 & $0.0,0.0$ & 0.000 & 5.246 \\
\hline $0.0,180.0$ & 6.091 & 0.011 & $0.0,180.0$ & 0.053 & 4.348 \\
\hline $30.0,30.0$ & 7.850 & 0.025 & $30.0,30.0$ & 2.757 & 0.077 \\
\hline $60.0,60.0$ & 31.296 & 0.007 & $60.0,60.0$ & 19.770 & 0.004 \\
\hline $90.0,0.0$ & 19.114 & 0.005 & $90.0,0.0$ & 18.168 & 0.002 \\
\hline $90.0,90.0$ & 45.290 & 0.001 & $90.0,90.0$ & 33.712 & 0.001 \\
\hline $90.0,180.0$ & 24.627 & 0.013 & $90.0,180.0$ & 25.074 & 0.005 \\
\hline $180.0,0.0$ & 0.525 & 5.541 & $180.0,0.0$ & 0.000 & 5.056 \\
\hline $180.0,180.0$ & 5.094 & 0.897 & $180.0,180.0$ & 0.053 & 4.348 \\
\hline
\end{tabular}

The results mentioned showed the minima $\left(0^{\circ}, 0^{\circ}\right)$ and $\left(180^{\circ}, 0^{\circ}\right)$ of $\boldsymbol{I I I \boldsymbol { a }}$ and $\boldsymbol{I I I \boldsymbol { b }}$ can exist in equivalent proportions, demonstrating that different isomer states can have similar populations.

On the other hand, the compounds involving symmetric groups in their structures, 2-styrylpyridine and IIIc, showed opposing behaviors. For example, in 2-styrylpyridine, the global and local minima, arising from the torsion of pyridine, had conformational energies and populations larger than in IIIc, in which both minima arise from the torsion of the cyano-substituted phenyl with similar values between them.

Selected optimized parameters in the gas phase and those, including the solvent $\mathrm{CHCl}_{3}$ effect, for model styrylpyridine-like compounds IIIa-IIIc are summarized in Table 3.

B3LYP/6-311 + G(d,p) has been shown to be an adequate level of theory for the geometry calculation for molecules of this kind [34]. The internuclear distances, valence angles and dihedral angles did not show significant changes among these three molecules. No important differences were found between the gas phase values and those with the solvent effect for the three molecules (Table 3). Three compounds showed planar structures according to the X-ray data of the title compounds 2-styrylpyridine [24] and 4-styrylpyridine [53]. 
Table 3. Theoretical structural parameters of the equilibrium structures of the styrylpyridine-like model compounds (IIIa-IIIc) calculated at the B3LYP/6-311 + G(d,p) theory level. The numbering convention is shown in Figure 1. Internuclear distances in $(\AA)$, valence and dihedral angles in $\left(^{\circ}\right)$.

\begin{tabular}{|c|c|c|c|c|c|c|}
\hline \multirow[b]{2}{*}{ Parameter } & \multicolumn{2}{|c|}{ IIIa } & \multicolumn{2}{|c|}{ IIIb } & \multicolumn{2}{|c|}{ IIIc } \\
\hline & Gas & PCM & Gas & РСМ & Gas & PCM \\
\hline 7-8 & 1.344 & 1.344 & 1.344 & 1.344 & 1.344 & 1.345 \\
\hline $7-1$ & 1.467 & 1.467 & 1.468 & 1.468 & 1.465 & 1.465 \\
\hline $8-1^{\prime}$ & 1.465 & 1.465 & 1.464 & 1.465 & 1.466 & 1.466 \\
\hline $4-3$ & 1.397 & 1.397 & 1.339 & 1.402 & 1.335 & 1.338 \\
\hline $3-2$ & 1.330 & 1.332 & 1.335 & 1.337 & 1.392 & 1.391 \\
\hline $2-1$ & 1.347 & 1.349 & 1.346 & 1.346 & 1.402 & 1.403 \\
\hline $3^{\prime}-\mathrm{C}$ & 1.433 & 1.432 & 1.432 & 1.432 & 1.432 & 1.431 \\
\hline $\mathrm{C} \equiv \mathrm{N}$ & 1.156 & 1.156 & 1.155 & 1.156 & 1.155 & 1.156 \\
\hline $1-7-8$ & 124.1 & 124.5 & 124.1 & 124.5 & 126.5 & 126.1 \\
\hline $2-1-7$ & 118.5 & 118.7 & 118.4 & 118.7 & 119.3 & 119.3 \\
\hline $7-8-1^{\prime}$ & 127.1 & 127.0 & 127.2 & 127.0 & 126.9 & 126.7 \\
\hline $2^{\prime}-3^{\prime}-\mathrm{C}$ & 119.6 & 119.5 & 119.6 & 119.5 & 119.7 & 119.6 \\
\hline $3^{\prime}-\mathrm{C} \equiv \mathrm{N}$ & 180.0 & 179.9 & 179.9 & 179.9 & 179.9 & 179.9 \\
\hline $2-1-7-8$ & 0.1 & 0.0 & 0.4 & 0.1 & 179.3 & 176.9 \\
\hline $1-7-8-1^{\prime}$ & 180.0 & 180.0 & 180.0 & 180.0 & 180.0 & 180.0 \\
\hline $7-8-1^{\prime}-2^{\prime}$ a & 0.4 & 0.3 & 0.7 & 0.2 & 179.2 & 176.6 \\
\hline $\mathrm{C}-3-2-1$ & --- & --- & 179.9 & 180.0 & --- & --- \\
\hline $1^{\prime}-2^{\prime}-3^{\prime}-\mathrm{C}$ & 180.0 & 180.0 & 180.0 & 180.0 & 180.0 & 179.9 \\
\hline
\end{tabular}

${ }^{\text {a }} 7-8-1$ '-6' for molecule IIIc.

\subsection{IR Spectroscopy}

Theoretical IR spectra of 2-styrylpyridine and IIIa-IIIc compounds showed similar characteristic infrared band frequencies in the gas phase and when including the solvent $\mathrm{CDCl}_{3}$ effect. Theoretical scaled frequencies were obtained by using the scale factor of 0.9648 [44]. The results of the calculated and experimental harmonic frequencies are collected in Table 4. 
Table 4. Calculated B3LYP/6-311 $+\mathrm{G}(\mathrm{d}, \mathrm{p})$ and experimental harmonic frequencies in $\left(\mathrm{cm}^{-1}\right)$ of the 2-styrylpyridine and IIIa-IIIc compounds.

\begin{tabular}{|c|c|c|c|c|c|c|c|c|c|c|c|c|}
\hline & \multicolumn{3}{|c|}{ 2-Styrylpyridine } & \multicolumn{3}{|c|}{ IIIa } & \multicolumn{3}{|c|}{$I I I b$} & \multicolumn{3}{|c|}{ IIIc } \\
\hline Assignment & Gas & PCM & $\operatorname{Exp}^{a}$ & Gas & PCM & $\operatorname{Exp}^{b}$ & Gas & PCM & $\operatorname{Exp}^{b}$ & Gas & PCM & $\operatorname{Exp}^{b}$ \\
\hline $\begin{array}{l}\delta(\mathrm{C}-\mathrm{H}) \text { out of } \\
\text { plane in trans } \\
\text { config. }\end{array}$ & 981.5 & 982.5 & $985 \mathrm{~s}$ & 971.4 & 972.5 & $983 \mathrm{~s}$ & 968.3 & 972.3 & $973 s$ & 970.3 & 973.0 & $975 \mathrm{~s}$ \\
\hline$v(C=C) P y$ & 1407.5 & 1405.7 & $1426 \mathrm{~s}$ & 1410.0 & 1408.8 & $1431 \mathrm{~s}$ & 1550.6 & 1546.7 & $1481 \mathrm{w}$ & 1390.2 & 1389.7 & $1418 \mathrm{~s}$ \\
\hline$v(\mathrm{C}=\mathrm{N}) \mathrm{Py}$ & 1446.8 & 1446.5 & $1468 \mathrm{~s}$ & 1457.6 & 1457.1 & $1476 \mathrm{~s}$ & 1576.6 & 1574.2 & $1580 \mathrm{~s}$ & 1471.6 & 1472.2 & $1481 \mathrm{~s}$ \\
\hline $\begin{array}{l}{[v(C=N)+} \\
v(C=C)] P y\end{array}$ & 1471.9 & 1470.6 & $1494 \mathrm{~s}$ & 1544.0 & 1541.6 & $1491 \mathrm{w}$ & ----- & ------ & ------ & 1530.6 & 1526.4 & $1549 \mathrm{~s}$ \\
\hline $\begin{array}{c}v(\mathrm{C}=\mathrm{N}) \mathrm{Py}+ \\
v(\mathrm{C}=\mathrm{C}) \mathrm{Ph}\end{array}$ & 1556.1 & 1553.7 & $1580 \mathrm{~s}$ & 1576.9 & 1574.6 & $1584 \mathrm{~s}$ & ------ & ------ & ------ & 1578.0 & 1575.9 & $1594 \mathrm{~s}$ \\
\hline$v(\mathrm{C}=\mathrm{C})$ & 1625.9 & 1624.1 & $1635 \mathrm{~m}$ & 1628.3 & 1626.7 & $1638 \mathrm{~m}$ & 1628.9 & 1626.8 & $1641 \mathrm{~m}$ & 1628.2 & 1625.7 & $1640 \mathrm{~m}$ \\
\hline$v(\mathrm{C} \equiv \mathrm{N})$ & --- & --- & --- & 2250.5 & 2242.6 & $2232 \mathrm{~s}$ & 2250.3 & 2242.5 & $2231 \mathrm{~s}$ & 2252.3 & 2244.0 & $2230 \mathrm{~s}$ \\
\hline$v(\mathrm{C}-\mathrm{H}) \mathrm{Py}$ & 3055.7 & 3061.4 & $3074 \mathrm{~m}$ & 3034.2 & 3036.2 & $3066 \mathrm{~m}$ & 3079.4 & 3081.3 & $3032 \mathrm{w}$ & 3043.1 & 3046.6 & $3065 \mathrm{~m}$ \\
\hline$v(\mathrm{C}-\mathrm{H}) \mathrm{Ph}$ & 3078.8 & 3080.1 & $3141 \mathrm{w}$ & 3090.5 & 3092.0 & $3146 \mathrm{w}$ & 3089.7 & 3091.8 & $3079 \mathrm{~m}$ & 3090.5 & 3093.3 & $3154 \mathrm{w}$ \\
\hline$\delta_{\text {as }}^{-}\left(\mathrm{CH}_{3}\right)$ & --- & --- & --- & --- & --- & --- & 1020.9 & 1019.8 & $1036 \mathrm{~m}$ & --- & --- & --- \\
\hline$\delta_{\mathrm{s}}\left(\mathrm{CH}_{3}\right)$ & --- & --- & --- & --- & --- & --- & 1360.8 & 1356.7 & $1374 \mathrm{~m}$ & --- & --- & --- \\
\hline$\delta^{+}{ }_{\text {as }}\left(\mathrm{CH}_{3}\right)$ & --- & --- & --- & --- & --- & --- & 1446.0 & 1439.6 & $1451 \mathrm{~s}$ & --- & --- & --- \\
\hline$v_{\mathrm{s}}\left(\mathrm{CH}_{3}\right)$ & --- & --- & --- & --- & --- & --- & 2928.2 & 2926.9 & $2925 \mathrm{~m}$ & --- & --- & --- \\
\hline$v_{\mathrm{as}}\left(\mathrm{CH}_{3}\right)$ & --- & --- & --- & --- & --- & --- & 2982.6 & 2980.0 & $2959 \mathrm{~s}$ & --- & --- & --- \\
\hline
\end{tabular}

${ }^{\mathrm{a}}$ Data IR(KBr) experimental in [27]; ${ }^{\mathrm{b}} \mathrm{IR}(\mathrm{KBr})$ experimental data obtained in this work. 
Of the ring vibrations, the $\mathrm{CH}$ bond stretching of the aromatic ring appeared at the 3100.0-3000.0 $\mathrm{cm}^{-1}$ region. The $v(\mathrm{C}-\mathrm{H})$ mode for pyridine was found in the range of $3079.4-3034.2 \mathrm{~cm}^{-1}$ in the gas phase and at the $3081.3-3036.2 \mathrm{~cm}^{-1}$ range in the solution phase. The $v(\mathrm{C}-\mathrm{H})$ mode for the phenyl ring was calculated at $3090.5-3078.8 \mathrm{~cm}^{-1}$ and $3093.3-3080.1 \mathrm{~cm}^{-1}$ ranges in gas and solution phases, respectively, (Table 4). The experimental values at $3074-3032 \mathrm{~cm}^{-1}$ for $v(\mathrm{C}-\mathrm{H}) \mathrm{Py}$ and at $3154-3079 \mathrm{~cm}^{-1}$ for $v(\mathrm{C}-\mathrm{H}) \mathrm{Ph}$ were in accord with an earlier report for aromatic compounds [54].

Spectral IR characterization of halogen-substituted compounds showed bands between 3004 and $3076 \mathrm{~cm}^{-1}$ for $v(\mathrm{C}-\mathrm{H})$ ring vibrations [30]. These ranges were in good agreement with the values obtained for our cyano-substituted 2-styrylpyridine (IIIa and IIIb) and 4-styrylpyridine (IIIc).

Stretching modes $v(C=C)$ and $v(C=N)$ of the pyridine ring were calculated at $1550.6-1390.2 \mathrm{~cm}^{-1}$ and $1576.6-1446.8 \mathrm{~cm}^{-1}$, respectively, in the gas phase, whilst values of $1546.7-1389.7 \mathrm{~cm}^{-1}$ and $1574.2-1446.5 \mathrm{~cm}^{-1}$ were calculated in the solution phase (Table 4). In the experimental IR spectrum, the bands at the $1580-1418 \mathrm{~cm}^{-1}$ range were also assigned to these stretching modes due to $v(\mathrm{C}=\mathrm{C}) \mathrm{Py}$ and $v(\mathrm{C}=\mathrm{N})$ Py of the pyridine ring $\left(1600-1430 \mathrm{~cm}^{-1}\right.$ range $)[55]$.

For 2-styrylpyridine and IIIa-IIIc compounds, a combination of bands resulting from the interaction between two vibrations were found coupled in the $1544.0-1471.9 \mathrm{~cm}^{-1}$ and $1541.6-1470.6 \mathrm{~cm}^{-1}$ regions corresponding to the stretching modes $[v(C=N)+v(C=C)]$ for the pyridine, in the gas, as well as the solution phase. On the other hand, coupled stretching modes $v(C=N)$ of pyridine $+v(C=C)$ of phenyl were found in the $1578.0-1556.1 \mathrm{~cm}^{-1}$ and $1575.9-1553.7 \mathrm{~cm}^{-1}$ regions in both phases (Table 4). In the $1600-1500 \mathrm{~cm}^{-1}$ region [54] the most of the six-membered aromatic ring systems is reported.

In contrast, the characteristic $v(\mathrm{C}=\mathrm{C})$ mode of the alkene double bond when it is conjugated with aromatic rings was obtained at $1628.9-1625.9 \mathrm{~cm}^{-1}$ and $1626.8-1624.1 \mathrm{~cm}^{-1}$, in gas and solution phases, respectively, and the experimental measurement appeared at $1641-1635 \mathrm{~cm}^{-1}$. These values were in accord with $1625 \mathrm{~cm}^{-1}$ reported [55] for this mode.

The band in the regions of $981.5-968.3 \mathrm{~cm}^{-1}$ and $982.5-972.3 \mathrm{~cm}^{-1}$ was assigned to the vibration associated with the out of plane deformation $\delta(\mathrm{C}-\mathrm{H})$ due to the protons of a double bond $-\mathrm{CH}=\mathrm{CH}-$ in the trans configuration, as calculated in both gas and solution conditions. The experimental values appeared at the $985-973 \mathrm{~cm}^{-1}$ region, in good agreement with the calculated values and with the values of 980-960 $\mathrm{cm}^{-1}$ reported [55], as well as with the values reported previously for 2- and 4-styrylpyridines with halogen substituents [30].

The mode $v(\mathrm{C} \equiv \mathrm{N})$ for the cyano-substituted styrylpyridine compounds IIIa-IIIc was found at $2252.3-2250.3 \mathrm{~cm}^{-1}$ and $2242.5 \mathrm{~cm}^{-1}$ in the gas and solution phases, respectively. The experimental spectra for IIIa-IIIc compounds showed the characteristic band shape in the $2232-2230 \mathrm{~cm}^{-1}$ range, which is the characteristic vibration frequency value for this mode assigned to compounds containing a cyano moiety [54].

For compound $\boldsymbol{I I I b}$, the band corresponding to the $\mathrm{CH}$ stretching modes of the $-\mathrm{CH}_{3}$ appeared at 2982.6-2928.2 $\mathrm{cm}^{-1}$ region in gas phase and the $2980.0-2926.9 \mathrm{~cm}^{-1}$ region in solution phase, and the experimental values were two bands at 2959 and $2925 \mathrm{~cm}^{-1}$. These values agreed with the experimental value reported of $2960 \mathrm{~cm}^{-1}$ for the asymmetric stretching and $2870 \mathrm{~cm}^{-1}$ for the symmetric one [56]. 
Alternatively, out-of-plane $\mathrm{CH}$ deformations for the methyl group for the compound $\boldsymbol{I I I} \boldsymbol{b}$ were found in the ranges of $1020.9-1019.8 \mathrm{~cm}^{-1}$ and $1446.0-1439.6 \mathrm{~cm}^{-1}$ for the asymmetric flexions $\delta_{\text {as }}^{-}\left(\mathrm{CH}_{3}\right)$ and $\delta_{\text {as }}^{+}\left(\mathrm{CH}_{3}\right)$, respectively, whilst the symmetric bending $\delta_{\mathrm{s}}\left(\mathrm{CH}_{3}\right)$ was found at $1360.8-1356.7 \mathrm{~cm}^{-1}$. These values matched with the values of 1375 and $1450 \mathrm{~cm}^{-1}$, respectively, for symmetric and asymmetric flexions reported in the literature [55] and in agreement with the observed values for the III b spectrum of 1374 and $1451 \mathrm{~cm}^{-1}$, respectively.

\subsection{UV Spectroscopy}

The electronic transition energies have been calculated within the framework of the Time-Dependent Density Functional Theory method (TD-DFT) [45-48]. These calculations have been performed on the lowest energy structures of each model compound as obtained from B3LYP/6-311 + G(d,p) calculations in gas phase and including the solvent $\mathrm{CHCl}_{3}$ effect. The TD-DFT approach accounts for the dynamic electron correlation caused by the coupling with the correlated ground state function. A previous comparative study [34] using ZINDO/S, TD-B3LYP and TD-PBE0 methods with different basis sets showed that the theoretical $\lambda_{\max }$ bands related to the electronic transition between $\mathrm{S}_{0} \rightarrow \mathrm{S}_{1}$ states were more exact, as compared with the available experimental data, using the TD-B3LYP/6-31G(d,p)//B3LYP/6-311 + G(d,p) theory level in gas phase.

The results for the electronic transitions, their assignments, the maxima absorption and the oscillator strengths of the styrylpyridine-like model compounds in the gas phase and including the solvent $\mathrm{CHCl}_{3}$ effect are shown in Table 5. The major $\mathrm{MO} \rightarrow \mathrm{MO}$ excitations involved in the three lowest-lying transitions are also indicated.

The experimental maximum absorptions, $\lambda_{\max }$, were observed at 311.0, 309.6, 312.1 and $293.6 \mathrm{~nm}$ for 2-styrylpyridine and molecules IIIa-IIIc, respectively (Table 5). The TD-B3LYP/6$31 \mathrm{G}(\mathrm{d}, \mathrm{p}) / / \mathrm{B} 3 \mathrm{LYP} / 6-311+\mathrm{G}(\mathrm{d}, \mathrm{p})$ calculations carried out correctly predicted the maximum absorption wavelengths, $\lambda_{\max }(\mathrm{nm})$, with errors of $0.19 \%, 0.10 \%, 0.22 \%$ and $4.63 \%$ in the gas phase. While the values for 2-styrylpyridine, IIIa and IIIb were reproduced correctly, the $\lambda_{\max }$ for $\boldsymbol{I I I c}$ was shifted $\sim 14 \mathrm{~nm}$ toward the shorter wavelength region of the spectrum in the experimental data. In the solution phase, similar errors of 3.95\%, 3.64\% and 3.87\% were found for 2-styrylpyridine and $\boldsymbol{I I I a}$ and $\boldsymbol{I I I b}$, respectively, while a considerable increment of $8.41 \%$ was obtained for IIIc. 
Table 5. Electronic transition, their assignments, the absorption maxima and oscillator strengths of the 2-styrylpyridine and IIIa-IIIc compounds calculated at the B3LYP/6-31G(d)//B3LYP/6-311+G(d,p) theory level.

\begin{tabular}{|c|c|c|c|c|c|c|c|}
\hline & \multirow{2}{*}{$\begin{array}{l}\text { Electronic } \\
\text { transition }\end{array}$} & \multicolumn{2}{|c|}{$\begin{array}{c}\text { Absorption maxima } \\
(\mathrm{nm}(\mathrm{eV}))\end{array}$} & \multicolumn{2}{|c|}{ Oscillator strengths } & \multirow[t]{2}{*}{ MO/Character (\% Coefficient) } & \multirow{2}{*}{$\begin{array}{c}\text { Experimental } \\
(\mathrm{nm}(\mathrm{eV}))\end{array}$} \\
\hline & & Gas & PCM & Gas & PCM & & \\
\hline \multirow{3}{*}{$\begin{array}{c}2- \\
\text { styrylpyridine }\end{array}$} & $\mathrm{S}_{0}-\mathrm{S}_{1}$ & $311.6(3.98)$ & $323.3(3.83)$ & 0.8922 & 1.0597 & $\mathrm{HOMO} \rightarrow \mathrm{LUMO}(98 \%)$ & \multirow{3}{*}{$311.0(3.99)$} \\
\hline & $\mathrm{S}_{0}-\mathrm{S}_{2}$ & $291.2(4.26)$ & $288.1(4.30)$ & 0.0014 & 0.0014 & HOMO-2 $\rightarrow$ LUMO (97\%) & \\
\hline & $\mathrm{S}_{0}-\mathrm{S}_{3}$ & $270.9(4.58)$ & $271.6(4.57)$ & 0.0030 & 0.0049 & HOMO-1 $\rightarrow$ LUMO $(74 \%)+$ HOMO $\rightarrow$ LUMO $+2(25 \%)$ & \\
\hline \multirow{3}{*}{ IIIa } & $\mathrm{S}_{0}-\mathrm{S}_{1}$ & $309.3(4.01)$ & $320.9(3.86)$ & 0.9656 & 1.1193 & $\mathrm{HOMO} \rightarrow \mathrm{LUMO}(98 \%)$ & \multirow{3}{*}{$309.6(4.01)$} \\
\hline & $\mathrm{S}_{0}-\mathrm{S}_{2}$ & $298.4(4.16)$ & $300.5(4.13)$ & 0.0010 & 0.0133 & HOMO- $1 \rightarrow$ LUMO $(96 \%)$ & \\
\hline & $\mathrm{S}_{0}-\mathrm{S}_{3}$ & $295.7(4.19)$ & $295.2(4.20)$ & 0.0116 & 0.0012 & $\mathrm{HOMO} \rightarrow \mathrm{LUMO}+1(86 \%)+\mathrm{HOMO}-2 \rightarrow$ LUMO $(12 \%)$ & \\
\hline \multirow{3}{*}{ IIIb } & $\mathrm{S}_{0}-\mathrm{S}_{1}$ & $312.7(3.96)$ & $324.1(3.83)$ & 0.9432 & 1.0916 & $\mathrm{HOMO} \rightarrow \mathrm{LUMO}(97 \%)$ & \multirow{3}{*}{$312.0(3.98)$} \\
\hline & $\mathrm{S}_{0}-\mathrm{S}_{2}$ & $302.7(4.10)$ & $302.8(4.10)$ & 0.0010 & 0.0141 & HOMO- $1 \rightarrow$ LUMO $(96 \%)$ & \\
\hline & $\mathrm{S}_{0}-\mathrm{S}_{3}$ & $297.7(4.16)$ & $300.3(4.13)$ & 0.0088 & 0.0012 & $\mathrm{HOMO} \rightarrow \mathrm{LUMO}+1(82 \%)+\mathrm{HOMO}-2 \rightarrow$ LUMO $(14 \%)$ & \\
\hline \multirow{3}{*}{ IIIc } & $\mathrm{S}_{0}-\mathrm{S}_{1}$ & $307.2(4.04)$ & $318.3(3.89)$ & 0.7615 & 0.9422 & HOMO $\rightarrow$ LUMO $(98 \%)$ & \multirow{3}{*}{$293.6(4.23)$} \\
\hline & $\mathrm{S}_{0}-\mathrm{S}_{2}$ & $285.4(4.34)$ & $296.9(4.18)$ & 0.1545 & 0.1452 & $\mathrm{HOMO} \rightarrow \mathrm{LUMO}+1(71 \%)+\mathrm{HOMO}-3 \rightarrow$ LUMO $(24 \%)$ & \\
\hline & $\mathrm{S}_{0}-\mathrm{S}_{3}$ & $309.0(4.01)$ & $288.1(4.30)$ & 0.0021 & 0.0018 & HOMO- $1 \rightarrow$ LUMO $(93 \%)$ & \\
\hline
\end{tabular}


The results in Table 5 indicated that the maximum absorption wavelength for the 2-styrylpyridine and IIIa-IIIc compounds are mainly associated with the $\mathrm{S}_{0}-\mathrm{S}_{1}$ transition, with the largest oscillator strength values. This transition involves the promotion of one electron from the bonding highest-occupied MO (HOMO) into the antibonding lowest-unoccupied MO (LUMO), i.e., it is due to the $\pi \rightarrow \pi^{*}$ transition in the trans configuration. In the case of 2-styrylpyridine, the contribution of the $\mathrm{HOMO} \rightarrow$ LUMO excitation was $98 \%$ for the $\mathrm{S}_{0}-\mathrm{S}_{1}$ transition, while for the $\mathrm{S}_{0}-\mathrm{S}_{2}$ transition, the main contribution (97\%) was derived from the excitation of HOMO-2 $\rightarrow$ LUMO. The $\mathrm{S}_{0}-\mathrm{S}_{3}$ transition in 2-styrylpyridine was characterized by two excitations contributed by HOMO-1 $\rightarrow$ LUMO (74\%) + $\mathrm{HOMO} \rightarrow \mathrm{LUMO}+2(25 \%)$. For the cyano-substituted compounds, the excitation of HOMO $\rightarrow$ LUMO was the main contribution to the first $\mathrm{S}_{0}-\mathrm{S}_{1}$ transition $(98 \%, 97 \%$ and $98 \%$, for IIIa, IIIb and IIIc, respectively). The excitation of HOMO- $\rightarrow$ LUMO contributed $96 \%$ to the second lowest-lying transition $\mathrm{S}_{0}-\mathrm{S}_{2}$ in the molecules IIIa and III b. The third lowest-lying transition $\mathrm{S}_{0}-\mathrm{S}_{3}$, corresponding to the $\mathrm{HOMO} \rightarrow \mathrm{LUMO}+1+\mathrm{HOMO}-2 \rightarrow$ LUMO excitations, contributed $86 \%$ and $12 \%$, respectively, in III a and 82\% and 14\%, respectively, in IIIb. For compound IIIc, the HOMO $\rightarrow$ LUMO+1 (71\%) + HOMO-3 $\rightarrow$ LUMO (24\%) and HOMO- $\rightarrow$ LUMO (93\%) excitations made the greatest contributions, the second and third lowest-lying transitions, respectively. This behavior explains the transition bands observed in the experimental spectra for all compounds.

On the other hand, Percino et al. recently reported absorption spectra of Cl- and F-substituted styrylpyridines that showed one strong absorption signal in the range of 308-318 nm [30], assigned to the $\pi \rightarrow \pi^{*}$ transition for the double bond with substituents in the trans position. ortho-pyridine vinylene compounds containing $-\mathrm{F}$ and $-\mathrm{Cl}$ attached in the meta-position on the phenyl ring that were analogous to IIIa showed absorption maxima at 309 and $308 \mathrm{~nm}$, respectively [30]. These authors did not observe a shift of the absorption wavelength owing to the presence of $-\mathrm{F}$ or $-\mathrm{Cl}$ with respect to the maximum absorption wavelength of 2-styrylpyridine. These results were similar to the value of $309 \mathrm{~nm}$ obtained for compound IIIa containing $-\mathrm{C} \equiv \mathrm{N}$ (Table 5). For molecule IIIc, with the $N$-atom position in the para-position, we observed hypsochromic shifts of $\sim 16 \mathrm{~nm}$ in the experimentally determined spectrum and $\sim 3 \mathrm{~nm}$ in the theoretically derived data with respect to IIIa. These results are at odds with the data of Percino et al. [30], who reported a red shift in $\lambda_{\max }$ for Cl-substituted 4-styrylpyridine to $318 \mathrm{~nm}$, which indicated a bathochromic effect of the electron-withdrawing halogen substituent.

Daku et al. [33] obtained a value of $314.5 \mathrm{~nm}$ for trans 4-styrylpyridine by using LR-TDDFT calculations for the first excited state $\mathrm{S}_{0}-\mathrm{S}_{1}$ with an oscillator strength value of 0.90418 . This value is approximate to that obtained in the present work for the trans 4-styrylpyridine cyano-substituted (IIIc) compound by $\sim 7 \mathrm{~nm}$. In general, the results are in agreement with previous experimental and theoretical results for compounds with a double bond in the trans position.

On the other hand, the analysis of the energies of the frontier molecular orbitals and, therefore, the band gap energies, give useful information about the optical and electronic properties of the conjugated compounds. The energies of the main molecular orbitals (HOMO, HOMO-1, LUMO and LUMO + 1 in $\mathrm{au}$ ) calculated by using the TD-B3LYP/6-311 $+\mathrm{G}(\mathrm{d}, \mathrm{p})$ theory level in gas and solution phases are collected in Table 6. We also present the calculated HOMO-LUMO gap energies $\left(\Delta E=\mathrm{C}_{\mathrm{LUMO}}-\mathrm{C}_{\mathrm{HOMO}}\right.$, in $\left.\mathrm{eV}\right)$ of the compounds. 
Table 6. Orbital energies (au) and Gap energies (eV) of the 2-styrylpyridine and IIIa-IIIc compounds calculated at the B3LYP/6-31G(d)//B3LYP/6-311+ G(d,p) theory level.

\begin{tabular}{cccccccccccc}
\hline & \multicolumn{2}{c}{$\boldsymbol{\epsilon}_{\text {Hомо-1 }}$} & \multicolumn{2}{c}{$\boldsymbol{\epsilon}_{\text {HOMо }}$} & \multicolumn{2}{c}{$\boldsymbol{\epsilon}_{\text {LUMO }}$} & \multicolumn{2}{c}{$\boldsymbol{\epsilon}_{\text {LUMO+1 }}$} & \multicolumn{3}{c}{ Gap energy } \\
\hline & Gas & PCM & Gas & PCM & Gas & PCM & Gas & PCM & Gas & PCM \\
2-stypy & -0.2625 & -0.2654 & -0.2201 & -0.2234 & -0.0714 & -0.0747 & -0.0340 & -0.0361 & 4.04 & 4.04 \\
$\boldsymbol{I I I}$ & -0.2742 & -0.2737 & -0.2366 & -0.2340 & -0.0867 & -0.0841 & -0.0638 & -0.0647 & 4.08 & 4.08 \\
$\boldsymbol{I I I}$ & -0.2702 & -0.2698 & -0.2338 & -0.2317 & -0.0848 & -0.0828 & -0.0629 & -0.0643 & 4.05 & 4.05 \\
$\boldsymbol{I I I c}$ & -0.2727 & -0.2749 & -0.2491 & -0.2429 & -0.0979 & -0.0920 & -0.0684 & -0.0646 & 4.11 & 4.10 \\
\hline
\end{tabular}

The results indicated similar values for molecular orbital and gap energies for both phases. The electron-withdrawing effects of the cyano group stabilized to the HOMO and LUMO orbitals of IIIa-IIIc with respect to 2-styrylpyridine. $\epsilon_{\mathrm{HOMO}}$ and $\epsilon_{\mathrm{LUMO}}$ were slightly lower in the gas than in the solution phase, except for 2-styrylpyridine. The smallest gap values were 4.04 and $4.05 \mathrm{eV}$ for 2-styrylpyridine and molecule $\boldsymbol{I I I}$, respectively (Table 6). The observation may be due to the inductive effect caused by the electron-donating properties of the $-\mathrm{CH}_{3}$ group that counteract the electron-withdrawing effects of the $-\mathrm{C} \equiv \mathrm{N}$.

The isosurfaces of the frontier molecular orbitals related to the electronic transition between $\mathrm{S}_{0} \rightarrow \mathrm{S}_{1}$ states (transition between molecular orbitals $\mathrm{HOMO} \rightarrow$ LUMO) are depicted in Figure 4 for the four molecules at the TD-B3LYP/6-311 + G(d,p) level in the gas phase. Similar orbital plots were obtained when the solvent $\mathrm{CHCl}_{3}$ effect was taken into account. In all cases, HOMO and LUMO $\pi$ MOs were delocalized over the entire molecule. The isosurfaces of the orbital HOMO were localized in four molecules through the central double bond and the double bonds on the rings, whereas the cyano group made a slight contribution to the electronic distribution of the HOMO in molecules IIIa-IIIc. In contrast, LUMO distribution was also similar in the four compounds and was localized on the nitrogen and carbon atoms of the rings and on the central carbons in the molecules. This study showed that the methyl group attached to the pyridine ring in molecule $\boldsymbol{I I I} \boldsymbol{b}$ had no effect on either the HOMO or the LUMO distributions. The electron distributions of the HOMO-1 were not uniform over the whole molecule. In 2-stryrylpyridine, the electron distribution was concentrated in the phenyl ring, but in molecules IIIa-IIIc, it was concentrated in the atoms of the pyridine ring, particularly at the lone pair electrons of the $N$-atom. In the case of LUMO +1 , the electron distribution for 2-styrylpyridine was more concentrated on the atoms of the pyridine ring, with a slight concentration on the phenyl ring. The electron distributions for molecules $\boldsymbol{I I I \boldsymbol { a }}$ and $\boldsymbol{I I I \boldsymbol { b }}$ were somewhat similar to 2 styrylpyridine, while for IIIc, the density was moved onto the phenyl ring and to a lesser extent onto the double bonds of the pyridine ring (Figure 4).

Thus, through the analysis of UV-Vis spectra, molecular orbital energies and isosurfaces, we are able to make predictions about whether a substituent will cause a blue or a red shift in the maximum absorption peaks, quantitatively and qualitatively, particularly if a compound has the same substituent in the structure. 
Figure 4. Main molecular orbitals of 2-styrylpyridine, trans-2-(m-cyanostyryl)pyridine (IIIa), trans-2-[3-methyl-(m-cyanostyryl)]pyridine (IIIb) and trans-4-(m-cyanostyryl)pyridine (IIIc) obtained at the TD-B3LYP/6-311 + G(d,p) theory level.

LUMO+1
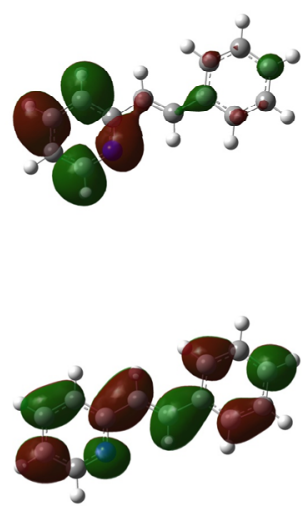

HOMO

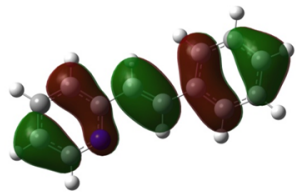

HOMO-1

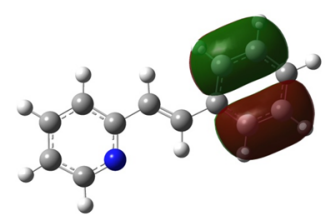

2-styrylpyridine
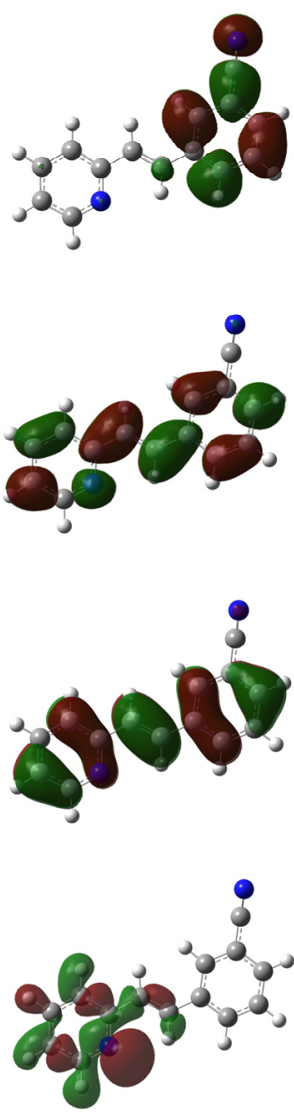

IIIa
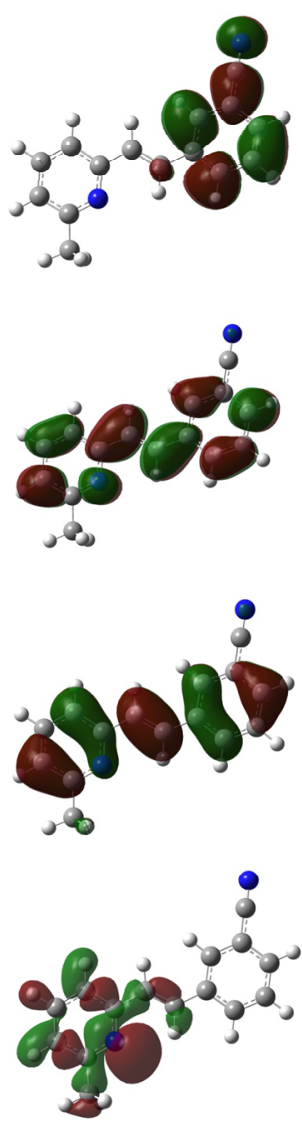

IIIb
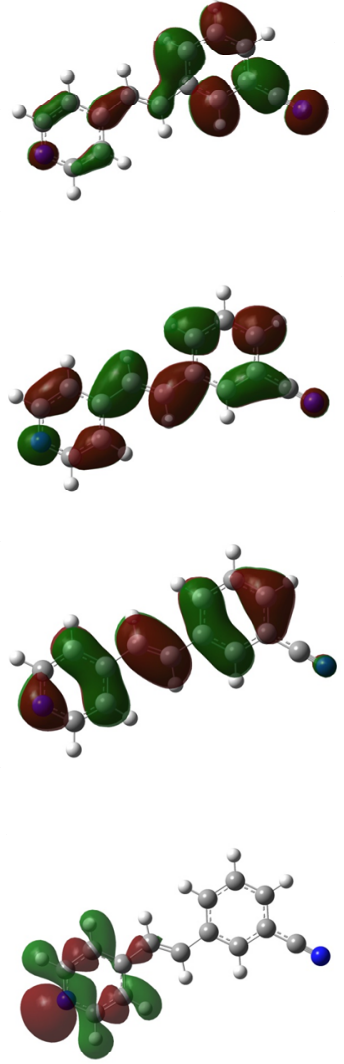

IIIc

\section{5. ${ }^{1} H$ NMR Spectroscopy}

The theoretical ${ }^{1} \mathrm{H}$ NMR results of the compounds were calculated by using the Gauge-Independent Atomic Orbital (GIAO) method [49,50] at the B3LYP/6-311 + G(2d,p) level from the optimized structures calculated at the B3LYP/6-311 $+\mathrm{G}(\mathrm{d}, \mathrm{p})$ level in gas phase and the solvent $\mathrm{CDCl}_{3}$ effect for the 2-styrylpyridine and the IIIa-IIIc compounds. In order to express the chemical shifts, $\delta$ (ppm), the geometry was optimized, and the ${ }^{1} \mathrm{H}$ NMR spectrum of the tetramethylsilane (TMS) molecule was calculated using the same method and basis set for use as a reference. The calculated isotropic shielding constants $\sigma_{\mathrm{i}}$ were then transformed to chemical shifts relative to TMS using $\delta_{\mathrm{i}}=\sigma_{\mathrm{TMS}}-\sigma_{\mathrm{I}}$, where $\sigma_{\mathrm{TMS}}=31.88$. The ${ }^{1} \mathrm{H}$ NMR data obtained at $400 \mathrm{MHz}$ in $\mathrm{CDCl}_{3}$ and theoretical chemical shifts of ${ }^{1} \mathrm{H}$, in ppm, are presented and compared in Table 7. 
Table 7. Theoretical and experimental ${ }^{1} \mathrm{H}$ NMR chemical shifts (ppm) of the 2-styrylpyridine and IIIa-IIIc compounds calculated at the B3LYP/6-311 + G(2d,p) //B3LYP/6-311 + G(d,p) theory level. All values are referenced to the chemical shift of TMS computed at the same theory level.

\begin{tabular}{|c|c|c|c|c|c|c|c|}
\hline \multicolumn{8}{|c|}{ Chemical shifts, $\delta(p p m)$} \\
\hline & \multicolumn{3}{|c|}{ 2-styrylpyridine } & & \multicolumn{3}{|c|}{ IIIa } \\
\hline & Gas & PCM & $\operatorname{Exp}^{a}$ & & Gas & PCM & $\operatorname{Exp}^{b}$ \\
\hline $\mathrm{H} 3(\mathrm{~d}, 1 \mathrm{H})$ & 8.964 & 8.993 & $8.653-8.639$ & $\mathrm{H} 3(\mathrm{~d}, 1 \mathrm{H})$ & 8.916 & 8.942 & $8.620-8.609$ \\
\hline H6', H2' (m, 2H) & $8.148-7.645$ & $8.285-7.752$ & $7.630-7.613$ & $\mathrm{H} 2^{\prime}(\mathrm{s}, 1 \mathrm{H})$ & 8.425 & 8.582 & 7.818 \\
\hline $\mathrm{H} 7(\mathrm{~d}, 1 \mathrm{H})$ & 7.418 & 7.594 & $7.240-7.186$ & $\mathrm{H} 7(\mathrm{~m}, 2 \mathrm{H})$ & 7.462 & 7.629 & $7.204-7.164$ \\
\hline $\mathrm{H} 8(\mathrm{~d}, 1 \mathrm{H})$ & 8.461 & 8.362 & $7.708-7.654$ & $\mathrm{H} 8(\mathrm{~d}, 2 \mathrm{H})$ & 8.406 & 8.335 & $7.632-7.592$ \\
\hline \multirow[t]{3}{*}{$\mathrm{H}^{\prime}, \mathrm{H} 33^{\prime}(\mathrm{m}, 3 \mathrm{H})$} & $7.593-7.544$ & $7.716-7.684$ & $7.416-7.310$ & $\mathrm{H} 5^{\prime}(\mathrm{m}, 1 \mathrm{H})$ & 7.818 & 8.021 & $7.488-7.442$ \\
\hline & \multicolumn{3}{|c|}{ IIIb } & & \multicolumn{3}{|c|}{ IIIc } \\
\hline & Gas & PCM & $\operatorname{Exp}^{b}$ & & Gas & PCM & $\operatorname{Exp}^{b}$ \\
\hline $\mathrm{H}\left(\mathrm{s}, 3 \mathrm{H}, \mathrm{CH}_{3}\right)$ & 2.714 & 2.704 & 2.599 & $\mathrm{H} 3, \mathrm{H} 5(\mathrm{~d}, 2 \mathrm{H})$ & 8.952 & 8.936 & $8.605-8.585$ \\
\hline H2' (s, 2H) & 8.419 & 8.577 & 7.827 & H2' (s, 1H) & 7.783 & 7.971 & 7.791 \\
\hline $\mathrm{H} 7(\mathrm{~d}, 1 \mathrm{H})$ & 7.408 & 7.569 & $7.220-7.180$ & $\mathrm{H} 7(\mathrm{~d}, 1 \mathrm{H})$ & 7.574 & 7.746 & $7.074-7.020$ \\
\hline $\mathrm{H} 8(\mathrm{~d}, 1 \mathrm{H})$ & 8.379 & 8.304 & $7.605-7.564$ & $\mathrm{H} 8(\mathrm{~d}, 1 \mathrm{H})$ & 7.365 & 7.525 & $7.261-7.207$ \\
\hline $\mathrm{H} 4^{\prime}(\mathrm{d}, 1 \mathrm{H})$ & 7.677 & 7.837 & $7.796-7.777$ & $\mathrm{H} 2, \mathrm{H} 6(\mathrm{~m}, 2 \mathrm{H})$ & 8.220 & 8.444 & $7.365-7.350$ \\
\hline
\end{tabular}

${ }^{\mathrm{a}}$ Experimental values from [24] obtained to $400 \mathrm{MHz}$ in $\mathrm{CDCl}_{3} ;{ }^{\mathrm{b}}$ Experimental values in this work obtained to $300 \mathrm{MHz}$ in $\mathrm{CDCl}_{3}$.

As it is shown in Table 7, the theoretical $\delta$ values were in good agreement with experimental data for the 2-styrylpyridine and the IIIa-IIIc compounds. For 2-styrylpyrydine, IIIa and IIIc, the $\delta$ for $\mathrm{H}$ in position $3\left(\mathrm{H}_{3}\right)$ was calculated at $8.9 \mathrm{ppm}$ in both gas phase and $\mathrm{CDCl}_{3}$ solvent, and the experimental signal was found in $8.6 \mathrm{ppm}$. Both values agreed very well in the range of chemical shift values for the typical protons for ortho position-substituted pyridine compounds at $8.5 \mathrm{ppm}$ [55]. Also, the values were consistent with those reported in the literature for the ring current in Hückel aromatic systems containing heteroatoms, which appeared at $8.59 \mathrm{ppm}$ [57]. On the other hand, the protons of the $-\mathrm{CH}_{3}$ at the 3 position for III (Figure 1) had a calculated $\delta$ of $2.7 \mathrm{ppm}$ in both phases and experimentally was a single signal at $2.6 \mathrm{ppm}$, as typically reported for methyl moieties [57].

The proton attached in position 2 ' for 2-styrylpyridine and compounds IIIa-IIIc showed theoretical chemical shifts in agreement with the experimental measurements. Error values calculated with respect to experimental data were $2.9 \%, 7.8 \%, 7.6 \%$ and $0.1 \%$, respectively, in the gas phase. These error percentages slightly increased by using the PCM model in the calculation. In the case of a proton next to a $-\mathrm{C} \equiv \mathrm{N}$ group in mono-substituted benzene, the $\delta$ value reported is $7.87 \mathrm{ppm}$ [57]. This value can be roughly compared with $\delta$ of $\mathrm{H}_{2}$ proton on the phenyl ring adjoining the $-\mathrm{C} \equiv \mathrm{N}$ group in compounds IIIa-IIIc; see Figure 1. The results summarized in Table 7, for the theoretical and experimental values obtained in this work, showed that the best approach was for the compound IIIc.

Interesting features were found in the assignment of the protons $\mathrm{H}_{7}$ and $\mathrm{H}_{8}$. From the ${ }^{1} \mathrm{H}$ NMR spectra of all compounds, two doublets corresponding to two protons in the trans position with $\mathrm{J}_{\mathrm{H}-\mathrm{H}}=16 \mathrm{~Hz}$ were found. It was difficult to determine which signal represented the $\mathrm{H}_{7}$ or the $\mathrm{H}_{8}$ proton, but the ${ }^{1} \mathrm{H}$ NMR calculation results allowed us to assign them adequately. $\mathrm{H}_{7}$ and $\mathrm{H}_{8}$ protons were experimentally assigned in the 7.2-7.0 ppm and 7.7-7.2 ppm ranges, respectively. The theoretical 
values were larger than those obtained in the experimental measurements. $\mathrm{H}_{7}$ was assigned in a range of approximately 7.6-7.4 ppm, while $\mathrm{H}_{8}$ appeared in a range of 8.5-7.4 ppm for the four molecules (Table 7). Using the PCM model, similar ranges were calculated. For $\mathrm{H}_{7}$ in gas phase, the theoretical errors with respect to the experimental values were $2.9 \%, 3.9 \%, 2.9 \%$ and $7.5 \%$, for 2-styrylpyridine and the molecules IIIa-IIIc, respectively. Error percentages increased by $\sim 2 \%$ for all four molecules by using the PCM model. Errors of $10.1 \%, 10.4 \%, 10.5 \%$ and $1.8 \%$ were obtained for $\mathrm{H}_{8}$ in 2-styrylpyridine and IIIa-IIIc, respectively, in gas phase, while by using the PCM model, the errors decreased in $\sim 1 \%$ for 2-styrylpyridine, IIIa and $\boldsymbol{I I I b}$; however, for $\boldsymbol{I I I c}$, it increased by $\sim 2 \%$ with respect to that obtained in the gas phase.

The characteristic chemical shift values for the $\mathrm{H}_{7}$ and $\mathrm{H}_{8}$ protons attached to a double bond in the trans position were influenced toward the lower field due to the extended conjugation caused by the presence of substituents on the aromatic rings [57].

Theoretically, the ppm found for the $\mathrm{H}_{7}$ and $\mathrm{H}_{8}$ protons showed that $\mathrm{H}_{8}$ appeared at chemical shifts larger than $\mathrm{H}_{7}$ in 2-styrylpyridine and molecules $\boldsymbol{I I I \boldsymbol { a }}$ and $\boldsymbol{I I I \boldsymbol { b }}$, which could be explained by the different steric effects due to the presence of the lone pair of electrons at the $N$-atom of the pyridine ring on the $\mathrm{H}_{7}$ and $\mathrm{H}_{8}$ protons. On the other hand, the electronic density distribution throughout the whole molecule was useful for the correct assignment of $\delta$ of these protons. The total electron density mapped with the electrostatic potential surface is presented (isoval $=0.003$ ) in Figure 5. Red regions indicate negative charge, and blue regions indicate positive charge. Yellow regions correspond to an intermediate value between the extremes red and blue.

The distances $\mathrm{H}_{7}-\mathrm{N}$ and $\mathrm{H}_{8}-\mathrm{N}$ were calculated for all four molecules. For 2-styrylpyridine, IIIa and $\boldsymbol{I I I b}$, the values were 3.36 and $2.50 \AA$, respectively. The smaller distance indicates the strong electron-withdrawing effect of the pyridine $N$-atom, which renders the proton more acidic, and therefore, the chemical shift for $\mathrm{H}_{8}$ was moved toward the downfield zone in the spectrum. PCM calculation did not take into account this effect, because the distances $\mathrm{H}_{7}-\mathrm{N}$ (3.36 $\AA$ ) and $\mathrm{H}_{8}-\mathrm{N}$ $(2.52 \AA)$ remained almost constant with respect to gas phase calculation. The distribution of the electron density shown in Figure 4 indicated that the presence of the electro-withdrawing $-\mathrm{C} \equiv \mathrm{N}$ group delocalized the electron distribution, thus decreasing the negative charge (in red color) on the double bond $(-\mathrm{CH}=\mathrm{CH}-)$ and on the bonds of the phenyl ring with respect to 2-styrylpyridine. In the IIIa and III $\boldsymbol{b}$ molecules, proton $\mathrm{H}_{8}$ was more profoundly affected by the proximity of the lone electron pair of the $N$-atom, which was manifested as a shorter distance $\left(\mathrm{H}_{8}-\mathrm{N}=2.52 \AA\right)$, leaving the proton more labile or unshielded. This fact might explain the larger chemical shift value found with respect to the proton $\mathrm{H}_{7}$, located at a farther distance from the $\mathrm{N}$-atom.

For molecule IIIc, the behavior of protons $\mathrm{H}_{7}$ and $\mathrm{H}_{8}$ could be due to the $\mathrm{A}-\pi-\mathrm{A}$ structure rather than by the presence of the lone electron pair of the $N$-atom, because the distances were longer: $\mathrm{H}_{8}-\mathrm{N}=5.13 \AA$ and $\mathrm{H}_{7}-\mathrm{N}=4.82 \AA$. So, the influence of the $N$-atom in the para-position and the symmetry in the molecule played a more important role than the $N$-proton distances in explaining the calculated and measured chemical shifts. The electron density and chemical environment about both protons was very similar in the molecule, and therefore, the $\delta$ values were very similar. 
Figure 5. Total electron density mapped with the electrostatic potential of 2-styrylpyridine, trans-2-( $m$-cyanostyryl)pyridine (IIIa), trans-2-[3-methyl-( $m$-cyanostyryl)]pyridine (IIIb) and trans-4-(m-cyanostyryl)pyridine (IIIc) obtained at the TD-B3LYP/6-311 + G(d,p) theory level.

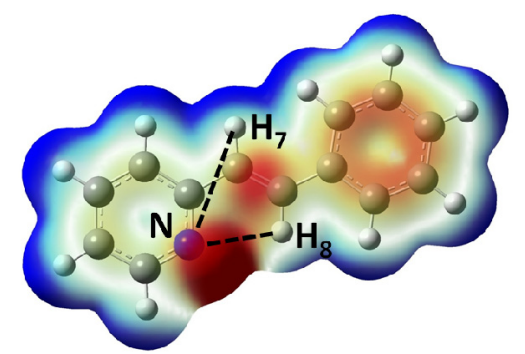

\section{2-styrylpyridine}

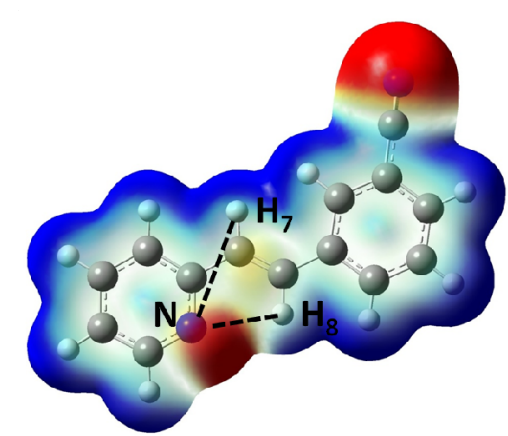

IIIa

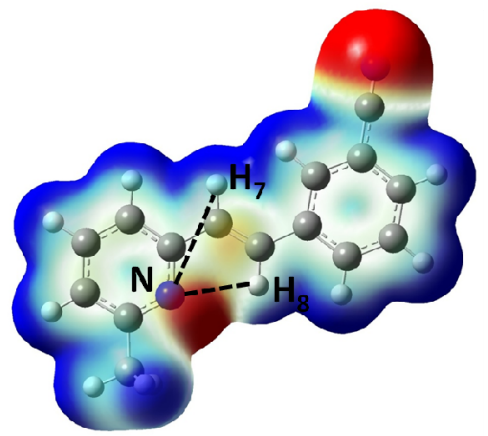

IIIb

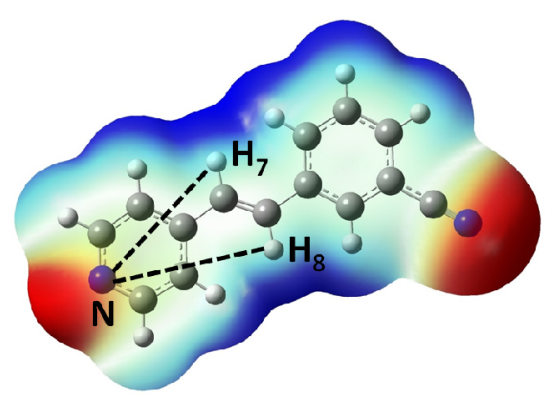

IIIc

From ${ }^{1} \mathrm{H}$ NMR of the analogous halogen-substituted compounds, the principal signals for protons in the trans position of a double bond were reported at 7.604-7.550 ppm and 7.079-7.025 ppm for the $p$-fluoro-2-styrylpyridine, while for $p$-chloro-2-styrylpyridine, signals appeared at 7.294-7.240 and 7.033-6.979 [30]. These results are in agreement with our results for CN-substituted compounds IIIa and IIIb (Table 7). On the other hand, our results for the molecule IIIc are in good agreement with respect to previously reported data for 4-styrylpyridine, as well as for the Cl-substituted derivative. The chemical shifts for protons in the double bond were at 7.591-7.537 and 7.126-7.072 ppm [30].

In Table 7, the values of chemical shifts for the other protons theoretically characterized and reported, for 2-styrylpyridine (H5' and H3', error = 2.8\%), IIIa (H3', error $=4.8 \%), \boldsymbol{I I I} \boldsymbol{b}$ (H4', error $=1.4 \%)$ and IIIc $(\mathrm{H} 2$ and $\mathrm{H} 6$, error $=11.7 \%)$ were in agreement with the experimental values obtained in the laboratory. These errors were increased by $\sim 2 \%$ when the solvent effect was included, except for the molecule $\boldsymbol{I I I}$, whose error value decreased in $0.4 \%$ by using the PCM calculation.

The theoretical ${ }^{1} \mathrm{H}$ NMR data for the compounds were extremely useful for the assignment of the double signals in experimental spectra and above all for the assignments for the $\mathrm{H}_{7}$ and $\mathrm{H}_{8}$ positions, which in the experimental spectrum were not easily distinguished. 


\section{Experimental Section}

\subsection{Chemicals}

3-Cyanobenzaldehyde, 2-picoline, 4-picoline, 2,6-lutidine, acquired from Aldrich Chemical Co. (Mexico city, Mexico), were purified before use. The IR spectra were recorded with a Vertex model 70 Bruker 750 FT-IR spectrophotometer by ATR. ${ }^{1} \mathrm{H}(400 \mathrm{MHz})$ NMR spectra were obtained with a Varian NMR spectrometer using $\mathrm{CDCl}_{3}$ as solvent. UV-Vis absorption spectra were recorded at room temperature in $\mathrm{CHCl}_{3}$ with an Ocean Optics SD2000 spectrometer equipped with the light source UV-VIS DT 1000 CE from Analytical Instrument System, using $1 \mathrm{~cm}$ quartz cell.

\subsection{Synthesis}

trans-2-(m-Cyanostyryl)pyridine

3-Cyanobenzaldehyde $(3.81 \mathrm{mmol})$ and 2-picoline $(7.5 \mathrm{mmol})$ were mixed together. The mixture was magnetically stirred and refluxed for $30 \mathrm{~h}$ at $120^{\circ} \mathrm{C}$ in the absence of any solvent or catalyst. The oily brown mixture was treated with a solution of $250 \mathrm{~mL}$ of $2 \mathrm{~N} \mathrm{NaOH}$ with stirring for $24 \mathrm{~h}$ to yield a brown precipitate. The product was purified by recrystallization from cyclohexane.

trans-2-[3-Methyl-(m-cyanostyryl)]pyridine

3-Cyanobenzaldehyde $(3.81 \mathrm{mmol})$ and 2,6-lutidine $(3.37 \mathrm{mmol})$ were mixed together. The mixture was magnetically stirred and refluxed for $22 \mathrm{~h}$ at $140{ }^{\circ} \mathrm{C}$ in the absence of any solvent or catalyst. The oily brown mixture was treated with a EtOH: $\mathrm{H}_{2} \mathrm{O}$ solution of a 1:1 molar ratio to yield a brown precipitate. The product was purified by recrystallization with cyclohexane.

trans-4-( $m$ '-Cyanostyryl)pyridine

3-Cyanobenzaldehyde $(3.81 \mathrm{mmol})$ was mixed with 4-picoline $(7.6 \mathrm{mmol})$. The oily brown mixture was magnetically stirred and refluxed for $30 \mathrm{~h}$ at $120^{\circ} \mathrm{C}$ in the absence of any solvent or catalyst. The oily product was precipitated by using cyclohexane and by scraping with a spatula. The product was purified by recrystallization with cyclohexane.

\section{Conclusions}

We have successfully prepared three new conjugated styrylpyridine derivatives containing two aromatic rings, one of them a phenyl ring with a cyano group in the $m$-position and the others with a pyridine ring in either the $o$ - or the $p$-position. These compounds were synthesized by Knoevenagel condensation between benzaldehydes with methylpyridines under green chemistry conditions. The structures were completely characterized by experimental and theoretical methods to obtain IR, UV-Vis and NMR ${ }^{1} \mathrm{H}$ spectroscopy data.

Fully optimized geometries for the three molecules were obtained by DFT calculations showing planar structures, and the parameters were very similar to the X-ray data reported for the compounds 2- and 4-styrylpyridine. Solvent effects of $\mathrm{CHCl}_{3}$ were included with the PCM model for better spectroscopic characterizations. Two-dimensional conformational and population analyses show that 
different isomer states of IIIa-IIIc can exist with similar values of populations, while for the 2-styrylpyridine, its global and local minima can be clearly differentiated.

The theoretical UV-Vis, IR and NMR ${ }^{1} \mathrm{H}$ data adequately reproduced the experimental data. Also, the theoretical study helped to identify clearly the characteristic vibration frequencies in the infrared spectra of the compounds. The assignment of characteristic normal vibrational modes as the $\delta(\mathrm{C}-\mathrm{H})$ due to the protons of $-\mathrm{CH}=\mathrm{CH}-$ in the trans configuration conjugated with aromatic rings and $v(\mathrm{C} \equiv \mathrm{N})$ for compounds containing a cyano group conjugated with an aromatic ring were performed and adequately assigned experimentally, as well as theoretically.

The TD-DFT approach provided satisfactory insight into the main valence transitions identified experimentally from absorption measurements. The electron-withdrawing cyano group at the meta-position of the phenyl group had minimal influence on the overall electronic absorption of 2-sytyrylpyridine for IIIa and $\boldsymbol{I I I b}$, a result that is consistent with previous investigations with other electron-withdrawing groups, such as halogens $(-\mathrm{Cl}$ and $-\mathrm{F})$. However, for molecule IIIc, the position of the $N$-atom in the molecule in the para-position and the presence of the $-\mathrm{C} \equiv \mathrm{N}$ substituent introduced a hypsochromic shift in the UV-Vis spectrum, which could be attributed to an $\mathrm{A}-\pi-\mathrm{A}$ structure.

${ }^{1} \mathrm{H}$ NMR chemical shifts for the protons attached in the trans position of a double bond appeared at 7.7-7.0 ppm as doublets, and the assignment was correctly made with the help of theoretical ${ }^{1} \mathrm{H}$ NMR calculations.

The experimental and theoretical characterization carried out on the compounds gave evidence of their formation. In addition, from a theoretical viewpoint, the calculations described the molecular structures accurately and gave complete, as well as convincing, spectroscopic results that could be used to design new molecules with specific properties. In this form, the synthesis of model compounds could be predicted gaining insights into their structural properties to create polymeric materials prepared with $\mathrm{D}-\pi-\mathrm{A}$ or $\mathrm{A}-\pi-\mathrm{A}$ structures.

\section{Acknowledgments}

This work has been co-financed by the projects PEZM-NAT II-G, SOMJ-NAT II-I and MEBF-NATII-G of the VIEP, BUAP. Also, M. E. Castro thanks CONACyT for a grant (\#148457) and the PROMEP-SEP (project BUAP-PTC-258).

\section{Conflict of Interest}

The authors declare no conflict of interest.

\section{References}

1. Gondek, E.; Danel, A.; Kityk, I.V. Single-layered light-emitting diodes possessing methoxy-modified pyrazoloquinoline dyes in poly-N-vinylcarbazole matrix. J. Lumin. 2008, 128, 348-354.

2. Patra, A.; Pan, M.; Friend, C.S.; Lin, T.Ch.; Cartwright, A.N.; Prasad, P.N. Electroluminescence properties of systematically derivatized organic chromophores containing electron donor and acceptor groups. Chem. Mater. 2002, 14, 4044-4048. 
3. Tessler, N.; Denton, G.J.; Friend, R.H. Lasing from conjugated-polymer microcavities. Nature 1996, 382, 695-697.

4. Shaheen, E.S.; Christoph, J.B.; Sariciftci, N.S.; Padinger, F.; Fromherz, T.; Hummelen, J.C. 2.5\% efficient organic plastic solar cells. Appl. Phys. Lett. 2001, 78, 841-843.

5. Yu, G.; Gao, J.; Hummelen, J.C.; Wudl, F.; Heeger, A.J. Polymer photovoltaic cells: Enhanced efficiencies via a network of internal donor-acceptor heterojunctions. Science 1995, 270, 1789-1791.

6. Samuel, I.D.W.; Turnbull, G.A. Organic semiconductor lasers. Chem. Rev. 2007, 107, 1272-1295.

7. Zhou, Y.; Xiao, Y.; Chi, S.; Qian, X. Isomeric boron-fluorine complexes with donor-acceptor architecture: Strong solid/liquid fluorescence and large stokes shift. Org. Lett. 2008, 10, 633-636.

8. Adès, D.; Boucard, V.; Cloutet, E.; Siove, A.; Olivero, C.; Castex, C.; Pichler, G. Photoluminescence of donor-acceptor carbazole-based molecules in amorphous and powder forms. J. Appl. Phys. 2000, 87, 7290-7293.

9. Pond, S.J.K.; Rumi, M.; Levin, M.D.; Parker, T.C.; Beljonne, D.; Day, M.W.; Brédas, J.L.; Marder, S.R.; Perry, J.W. One- and two-photon spectroscopy of donor-acceptor-donor di(styryl)benzene derivatives: Effect of cyano substitution and distortion from planarity. $J$. Phys. Chem. A 2002, 106, 11470-11480.

10. Wang, B.; Wang, Y.; Hua, J.; Jiang, Y.; Huang, J.; Qian, S.; Tian, H. Starbust triarylamine donor-acceptor-donor quadrupolar derivatives based on cyano-substituted diphenylamestrylbenzene: Tunable aggregation-induced emission colors and large two-photon absorption cross sections. Chemistry 2011, 17 2647-2655.

11. Dailey, S.; Halim, M.; Rebourt, E.; Hoursburgh, L.E.; Samuel, I.D.W.; Monkman, A.P. An efficient electron-transporting polymer for light-emitting diodes. J. Phys. Condens. Matter. 1998, 10, 5171-5178.

12. Epstein, A.J.; Blatchford, J.W.; Wang, Y.Z.; Jessen, S.W.; Gebler, D.D.; Lin, L.B.; Gustafson, T.L.; Wang, H.L.; Park, Y.W.; Swager, T.M.; et al. Poly(p-pyridine)-and poly( $p$-pyridyl vinylene)-based polymers: Their photophysics and application to SCALE devices. Synt. Met. 1996, 78, 253-261.

13. Bartholomew, G.P.; Bazan, G.C.; Bu, X.; Lachicotte, R. Packing modes of distyrylbenzene derivatives. J. Chem. Mater. 2000, 12, 1422-1430.

14. Bartocci, G.G.; Mazzucato, U.; Masetti, F.; Galiazzo, G. Excited state reactivity of aza aromatics. 9. Fluorescence and photoisomerization of planar and hindered styrylpyridines. J. Phys. Chem. 1980, 84, 847-851.

15. Marri, E.; Galiazzo, G.; Mazzucato, U.; Spalletti, A. Excited state properties of cross-conjugated 1,2- and 1,3-distyrylbenzene and some aza-analogues. Chem. Phys. 2005, 312, 205-211.

16. Bartocci, G.; Mazzucato, U. Conformational equilibria and photophysical behaviour of styrylpyridines: Excitation energy effects in fluid and rigid solutions. J. Lumuniscence 1982, 27, 163-175.

17. Blanchard-Desce, M.; Ledoux, I.; Lehn, J.M.; Malthete, J.; Zyss, J. Push-pull polyenes and carotenoids: Synthesis and non-linear optical properties. J. Chem. Soc. 1988, 11, 737-739.

18. Lapouyade, R.; Kuhn, A.; Letard, J.-F.; Rettig, W. Multiple relaxation pathways in photoexcited dimethylaminonitro- and dimethylaminocyano-stilbenes. Chem. Phys. Lett. 1993, 208, 48-58. 
19. Percino, M.J.; Chapela, V.M.; Perez-Gutierrez, E.; Cerón, M.; Soriano, G. Synthesis, optical, and spectroscopic characterisation of substituted 3-phenyl-2-arylacrylonitriles. Chem. Pap. 2011, 65, $42-51$.

20. Pérez-Gutierrez, E.; Percino, M.J.; Chapela, V.M.; Cerón, M.; Maldonado, J.L.; Ramos-Ortiz, G. Synthesis, characterization and photophysical properties of pyridine-carbazole acrylonitrile derivatives. Materials 2011, 4, 562-574.

21. Percino, M.J.; Chapela, V.M; Cerón, M.; Castro, M.E.; Soriano, G.; Pérez-Gutiérrez E.; Meléndez-Bustamante F. Synthesis and characterization of conjugated pyridine-( $N$-diphenylamino)acrylonitrile derivatives: Photophysical properties. J. Mat. Sci. Res. 2012, 1, 181-192.

22. Chapela, V.M.; Percino, M.J.; Rodríguez-Barbarín, C. Crystal structure of 2,6-distyrylpyridine. J. Chem. Crystallogr. 2003, 33, 77-83.

23. Melendez, F.J.; Urzúa, O.; Percino, M.J.; Chapela, V.M. A theoretical study on three conformational structures of 2,6-distyrylpyridine. Int. J. Quant. Chem. 2010, 110, 838-849.

24. Percino, M.J.; Chapela, V.M.; Salmón, M.; Espinosa-Pérez, G.; Herrera, A.M.; Flores, A. X-ray crystal structure of 2-styrylpyridine. J. Chem. Crystallogr. 1997, 27, 549-552.

25. Percino, M.J.; Chapela, V.M.; Urzúa, O.; Montiel, L.-F.; Rodríguez-Barbarín, C. 1-(p-Fluorophenyl)-2-(2'-pyridyl)ethanol and 1-( $p$-Fluorophenyl)-2-(2'-pyridyl)ethene obtained from the condensation reaction of 2-picoline and $p$-fluorophenylaldehyde under catalyst- and solvent-free conditions. Res. Chem. Intermed. 2007, 33, 623-629.

26. Percino, M.J.; Chapela, V.M.; Montiel, L.-F.; Rodríguez-Barbarín, C. X-Ray crystal structures of a 1-( $p$-fluorophenyl)-2-( $\alpha$-pyridyl)ethanol intermediate and the 1-( $p$-fluorophenyl)-2-( $\alpha$-pyridyl)ethane dehydration compound obtained from the condensation reaction of 2-methylpyridine and p-fluorobenzaldehyde. Open Crystallogr. J. 2008, 1, 37-41.

27. Percino, M.J.; Chapela, V.M.; Sánchez, A.; Maldonado-Rivera, J.-L. Condensation reaction of methylpyridines and aromatic aldehydes under catalyst and solvent free conditions. Chem. Indian J. 2006, 3, 262-267.

28. Percino, M.J.; Chapela, V.M. Unexpected intermediate 1-phenyl-2-(4-pyridyl)ethanol isolated from benzaldehyde and 4-picoline condensation reaction. Res. Chem. Intermed. 2000, 26, 303-307.

29. Percino, M.J.; Chapela, V.M.; Salmón, M.; Toscano, R.A. Unexpected crystallization and X-ray crystal structure of racemic 1-phenyl-2-(4-pyridyl)ethanol intermediate. J. Chem. Crystal. 2000, 30, 385-388.

30. Percino, M.J.; Chapela, V.M.; Montiel, L.-F.; Pérez-Gutiérrez, E.; Maldonado, J.L. Spectroscopic characterization of halogen- and cyano-substituted pyridinevinylenes synthesized without catalyst or solvent. Chem. Pap. 2010, 64, 360-367.

31. Atalay, Y.; Basoglu, A.; Avci, D. Molecular structure, IR and NMR spectra of 2,6 distyrylpyridine by density functional theory and ab initio Hartree-Fock calculations. Spectrochim. Acta Part A 2008, 69, 460-466.

32. Daku, L.M.L.; Linares, J.; Boillot, M.-L. Ab initio static and molecular dynamics study of 4-styrylpyridine. ChemPhysChem 2007, 8, 1402-1416. 
33. Daku, L.M.L.; Linares, J.; Boillot, M.-L. Ab initio static and molecular dynamics study of the absorption spectra of the 4-styrylpyridine photoswitch in its cis and trans forms. PhysChemChemPhys 2010, 12, 6107-6123.

34. Castro, M.E.; Percino, M.J.; Chapela, V.M.; Soriano, G.; Cerón, M.; Melendez, F.J. Comparative theoretical study of the UV/Vis absorption spectra of styrylpyridine compounds using TD-DFT calculations. J. Mol. Model. 2012, doi:10.1007/s00894-012-1602-1.

35. Grof, M.; Gatial, A.; Milata, V.; Pronayova, N.; Kozisek, J.; Breza, M.; Matejka, P. Conformational and isomerizational studies of 3-N,N-dimethylhydrazino-2-acetyl propenenitrile using X-ray analysis, NMR and vibrational spectra, and ab initio calculations. J. Mol. Struct. 2009, 938, 97-110.

36. Belletete, M.; Morin, J.-F.; Leclerc, M.; Durocher, G. A theoretical, spectroscopic, and photophysical study of 2,7-carbazolenevinylene conjugated derivatives. J. Phys. Chem. A 2005, 109, 6953-6959.

37. Grof, M.; Gatial, A.; Milata, V.; Pronayova, N.; Kozisek, J.; Breza, M.; Matejka, P. Conformational and isomerizational studies of 3-N,N-dimethylhydrazino-2-methylsulfonyl propenenitrile using NMR and vibrational spectra, X-ray analysis and ab initio calculations. J. Mol. Struct. 2008, 891, 192-204.

38. Avci, D.; Comert, H.; Tarcan, E.; Dincer, M.; Atalay, Y. Molecular structure and vibrational and chemical shift assignments of 3,5-bis-(4-methylbenzoyl)-2,6-bis(4-methylphenyl)-4H-pyran-4-one: A combined experimental and theoretical analysis. J. Mol. Struct. 2010, 975, 234-241.

39. Jacquemin, D.; Perpete, E.A.; Scuseria, G.E.; Ciofini, I.; Adamo, C.J. TD-DFT performance for the visible absorption spectra of organic dyes: Conventional versus long-range hybrids. Chem. Theory Comput. 2008, 4, 123-135.

40. Becke, A.D. Density-functional thermochemistry. III. The role of exchange. J. Chem. Phys. 1993, 98, 5648-5652.

41. Lee, C.; Yang, W.; Parr, R.G. Development of the Colle-Salvetti correlation-energy formula into a functional of the electron density. Phys. Rev. B 1988, 37, 785-789.

42. McLean, A.D.; Chandler, G.S. Contracted Gaussian-basis sets for molecular calculations. 1. 2nd row atoms, $Z=11-18$. J. Chem. Phys. 1980, 72, 5639-5648.

43. Cossi, M.; Rega, N.; Scalmani, M.; Barone, V. Polarizable dielectric model of solvation with inclusion of charge penetration effects. J. Chem. Phys. 2001, 114, 5691-5701.

44. Scott, A.P.; Radom, L. Harmonic vibrational frequencies: An evaluation of Hartree-Fock, Moller-Plesset, quadratic configuration interaction, density functional theory, and semiempirical scale factors. J. Phys. Chem. 1996, 100, 16502-16513.

45. Casida, M.E.; Jamorski, C.; Casida, K.C.; Salahub, D.R. Molecular excitation energies to high-lying bound states from time-dependent density-functional response theory: Characterization and correction of the time-dependent local density approximation ionization threshold. J. Chem. Phys. 1998, 108, 4439-4449.

46. Gross, E.K.U.; Kohn, W. Time-dependent density functional theory. Adv. Quant. Chem. 1990, 21, 255-291.

47. Wacker, O.J.; Kümmel, R.; Gross, E.K.U. Time-dependent density-functional theory for superconductors. Phys. Rev. Lett. 1994, 73, 2915-2918. 
48. Marques, M.A.L.; Gross, E.K.U. Time-dependent density functional theory. Annu. Rev. Phys. Chem. 2004, 55, 427-455.

49. Wolinski, K.; Hilton, J.F.; Pulay, P. Efficient implementation of the gauge-independent atomic orbital method for NMR chemical shift calculations. J. Am. Chem. Soc. 1990, 112, 8251-8260.

50. Cheeseman, J.R.; Trucks, G.W.; Keith, T.A.; Frisch, M.J. A Comparison of models for calculating nuclear magnetic resonance shielding tensors. J. Chem. Phys. 1996, 104, 5497-5509.

51. Gaussian 09, Revision A.1; Gaussian, Inc.: Wallingford, CT, USA, 2009.

52. Niño, A.; Muñoz-Caro, C.; Mora, M.; Reyes, S. Effect of the conformational kinetic energy and the rotovibrational coupling in the conformational population of bioactive compounds. $J$. Phys. Chem. A 2003, 107, 10191-10198.

53. Cariati, E.; Roberto, D.; Ugo, R.; Srdanov, V.I.; Galli, S.; Macchi, P.; Sironi, A. The acentric nature of trans-stilbazole crystals and the origin of its NLO response. New J. Chem. 2002, 26, $13-15$.

54. Dudley, H.W.; Fleming, I. Spectroscopic Methods in Organic Chemistry, 5th ed.; The McGraw-Hill Companies: London, UK, 1995.

55. Silverstein, R.M.; Webster, F.X. Spectrometric Identification of Organic Compounds, 6th ed.; John Wiley \& Sons, Inc.: Hoboken, NJ, USA, 1997.

56. Nakanishi, K.; Solomon, P.H. Infrared Absorption Spectroscopy, 2nd ed.; Holden-Day Inc.: Oakland, CA, USA, 1977.

57. Williams, D.H., Fleming, I. Spectroscopic Methods in Organic Chemistry, 3rd ed.; McGraw-Hill: Maidenhead, UK, 1980.

(C) 2013 by the authors; licensee MDPI, Basel, Switzerland. This article is an open access article distributed under the terms and conditions of the Creative Commons Attribution license (http://creativecommons.org/licenses/by/3.0/). 